\title{
HISTORY OF THE AMERICAN SOCIETY FOR CLINICAL INVESTIGATION, 1909-1959
}

\author{
By ELLEN R. BRAINARD
}

\section{ORIGINS}

\section{Beginnings on the Boardwalk}

Although the age of the American Society for Clinical Investigation is reckoned formally from the date of its first annual meeting-May 10, 1909 -its story really begins two years earlier, in June, 1907 , when the idea for its formation was first suggested.

The man behind the idea was Dr. Samuel J. Meltzer; the setting, the Boardwalk in Atlantic City, New Jersey. The story, recounted for Society members by Dr. Warfield Longcope (1) is as follows :

A few of you will remember the circumstances under which this Society originated and the modest manner in which it was launched for action. One afternoon, after a session of the Association of American Physicians ${ }^{1}$ here in Atlantic City, a little group of men stopped in their promenade on the Boardwalk to talk. Dr. Meltzer happened to join them and soon led the conversation to the topic of medical meetings. In his cheerful and enthusiastic manner which we all know so well, he suggested that a new society should be formed with a somewhat different aim and a different membership from those already in existence. $\mathrm{He}$ felt very strongly that there should be an opportunity for the men, most of whom were young, and actively engaged in clinical investigation, to come together and discuss their work. Indeed, a requisite for admission to the Society was that a man should be actively engaged in investigation and a clinician. Thus this society, he hoped, would stand for investigation in internal medicine, as distinguished from those societies which represented investigation in the fundamental sciences.

As nearly as we can discover, the group on the Boardwalk included, in addition to Drs. Longcope

\footnotetext{
1 Actually, it was a session of the American Medical Association rather than of the Association of American Physicians, although the latter was an understandable error made in retrospect by several of the early members. The Society's minutes state that informal discussions were held at the time of the American Medical Association meeting in 1907. Furthermore, all personal accounts agree that these discussions took place in June, 1907, in Atlantic City. The Association of American Physicians had met in May of that year in Washington, whereas the American Medical Association convened in Atlantic City June 4-7, 1907.
}

and Meltzer, Dr. David L. Edsall, Dr. Wilder Tileston and probably Dr. Joseph H. Pratt. Their recollections substantiate and augment Dr. Longcope's story and help us to imagine what the gist of their conversation must have been.

"The reason for the starting of the Society," according to Dr. Tileston (2), "was that at the meetings of the Association of American Physicians (whose membership was limited at that time to 160 ), the younger men had few opportunities to present their papers, since many of them were not members."

Further illumination is provided by Dr. Edsall (3) :

I have a very sketchy memory of what happened in any detail at the time of the formation of the American Society for Clinical Investigation. I remember chiefly meeting Dr. Meltzer on the board walk at Atlantic City when the matter first came up and his making the suggestion .... of the formation of the Society in order to give younger men who were not yet members of, and not eligible for, the Association of Physicians the advantages of meeting other young men active in work of that kind and discussing matters with them, and the stimulus that would come from that.

Dr. Meltzer's suggestion apparently met with a ready response. That same evening he invited the group to his hotel room, most likely at the Traymore, to explore the idea more fully. Drs. Henry A. Christian and Rufus Cole may have been included at this meeting and, although there is no formal record of what went on, it is clear that the idea took hold. The outcome was the formation of a committee consisting of Drs. Christian, Edsall, Pratt and Tileston, which met in Boston on June 17, 1907, at the University Club.

At this meeting, the four men discussed the aims and scope of the proposed society and agreed to enlarge the committee by the inclusion of Drs. Cole, Longcope and Meltzer. Before the next meeting, Dr. J. A. Capps of Chicago and Dr. A. W. Hewlett, then of San Francisco, were added as well, bringing the total number on the founding committee to nine and extending its geographical distribution westward (the other seven were all from New York, Philadelphia, Baltimore or Bos- 
ton). Sometime, probably in the interim between this first meeting and the second, which took place that autumn, a list of men considered eligible for membership was drawn up and divided among the committee members. Each was responsible for checking the publications record of a group of nominees for the previous five years, this record to be used as a basis for selection. It was agreed that seven of the nine must approve each nominee before an invitation to share in the society's organization would be extended to him.

The committe, with the exception of Dr. Hewlett, met again on November 7, 1907, at the Manhattan Hotel in New York at the time of a meeting of the Interurban Clinical Club. It is probably this meeting of which Dr. Longcope (4) wrote:

I remember ... that we all sat about a table somewhere and discussed at considerable length a list of names from which the membership of this new society should be recruited. As I recall the discussion, these men were selected because it was thought they would be interested in the new endeavor and were sympathetic with the idea of forming a society whose main object was to discuss the problems in clinical investigation in which each and every one was engaged.

The result of these deliberations was a list of 22 men to whom an invitation to be present at the organizational meeting was sent. ${ }^{2}$ A committee of three-Drs. Christian, Longcope and Meltzerwas appointed to draft a constitution to be presented at the charter meeting, set for the day prior to the 1908 meeting of the Association of American Physicians in Washington. It is likely, too, that the matter of a name for the nascent society was discussed at the November committee meeting. With regard to the somewhat cumbersome choice - "American Society for the Advancement of Clinical Investigation"-Dr. G. Canby Robinson offers the following explanation:

As I recall, the word "Investigation" was used instead of "Research" because there was another society composed of homeopaths known as the Society of Clinical Research (5).

\footnotetext{
2 The list is included below in the account of the charter meeting. It was either expanded by the addition of three names prior to the organizational meeting or the list given in the minutes of the November committee meeting is incomplete, for the records of the charter meeting (May 11, 1908) contain the names of 25 men (in addition to the nine committee members) who had been invited to be present.
}

Thus, by November-a scant four months after Dr. Meltzer had first proposed it-the idea had been given concrete form and the new society was almost a reality. It was formally constituted on May 11, 1908, at the New Willard Hotel in Washington.

The charter meeting convened at 3:30 p.m. with 17 men present for Dr. Edsall's call to order. Edsall was elected temporary chairman; Dr. Christian, temporary secretary. Consideration of the constitution was the first item on the agenda and it was agreed to read, discuss and vote on it article by article. Most of the amendments to the original draft involved only minor modifications in wording. The minutes hint, however, at what must have been a lively discussion regarding a point in Article III, Section 1-"Eligibility for Membership"-which read: "Any practicing physician residing in the United States or Canada who has accomplished a meritorious, original investigation in the clinical or allied sciences of medicine ... is eligible to membership." Dr. T. C. Janeway's inquiry as to what was to be the criterion for judging whether a man was a "practicing physician" set off a discussion in which several of the members participated. Would a resident at the Johns Hopkins Hospital, for example, be considered a practicing physician, Dr. Janeway wanted to know. Unfortunately, the minutes do not elaborate the points raised in reply and, although it must have been an interesting debate, we do not know whether Dr. Janeway received a satisfactory answer to his question. In any case, no alteration in the section resulted.

One change, which may have been significant, involved Article VII-"Meetings"-which read, originally, "The Society shall hold one general meeting annually. This meeting shall take place in the spring on the date preceding and at the place of the annual meeting of the Association of American Physicians." On Dr. Cole's motion it was voted to delete all but the first sentence, thereby leaving the time and place open to the discretion of the Council. Whether or not Dr. Cole's amendment reflected reluctance to fashion the new society so obviously in the footsteps of the old is, of course, not on record and, amendment or no amendment, the Society, in fact, met regularly in geographical and temporal 
proximity to the Association. The remaining articles were approved with little debate, and the constitution as a whole was formally adopted by the Society.

Following this action, the chair was empowered to appoint a three-man nominating committee which presented a single slate of candidates for office. Until the fourth annual meeting, apparently each member of the Society cast an individual ballot for the slate. This formality was abandoned in 1912 when it was moved that the secretary cast a unanimous ballot for all nominees, a procedure which has been followed ever since, though not without occasional criticism. The officers elected were as follows: Dr. Meltzer, president; Dr. Edsall, vice-president; Dr. Christian, secretary ; Dr. John Howland, treasurer ; and Drs. Miller, Janeway and Hewlett, councillors for one, two and three years, respectively.

Dr. Meltzer took the chair, and the remainder of the meeting was devoted to approval of the order of business for the first annual meeting, appointment of a committee to draft by-laws to the constitution, approval of a Council recommendation that dues for the forthcoming year be set at $\$ 5.00$, and the nomination of 20 men for membership. It is interesting to note that for the first few years all nominations were made at the meetings and were voted upon the following year. The minutes carefully record, along with the name of each nominee, the name of the members who proposed and seconded his nomination. The nominating procedure was altered by constitutional amendment in 1913; thereafter, nominations could be made in writing at any time during the year.

Letters of invitation had been sent to 34 men, including the nine committee members. Of these, one had apparently declined; 30 had accepted; and three, two of them in Manila, had not been heard from at the time of the meeting. (Replies indicating acceptance were eventually received from the two gentlemen in the Philippines; the third apparently never answered or declined the invitation to join.) The final count of 32 physicians who indicated their desire to participate in the new society is presented in Table I. It was moved that these men be considered charter members, with the proviso that in order to be so considered, members
TABLE I

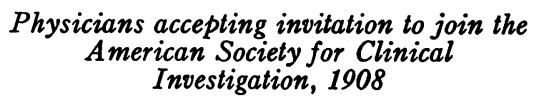

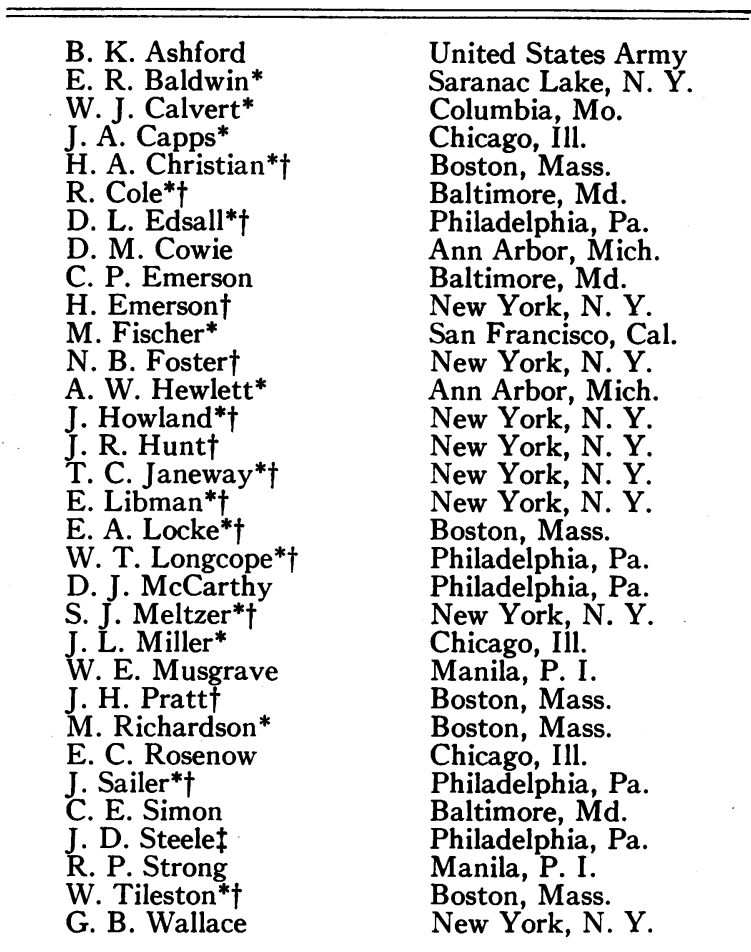

* Present at 1908 charter meeting.

$\dagger$ Present at first annual meeting, 1909.

$\ddagger$ Dr. Steele died in 1908 .

who had not attended the organization meeting would be present for the first annual session the following year. Those who attended one or both of the two meetings, as noted in the minutes, are indicated in the table. Presumably it is only these who are officially considered charter members, although various lists contain discrepancies in this regard.

With the adjournment of the meeting that evening, the American Society for the Advancement of Clinical Investigation was formally launched. Before continuing the story of its subsequent growth, it might be well to examine more fully the background of its origins, for the founding of the Society was closely related to the broader picture of contemporaneous developments in American medical research. In a very real sense, the Society grew up with investigative medicine in this country, and the "rebellion" of the Young Turks was a part of the spirit of the times. In 
an attempt to understand that spirit, we shall look more closely at the men who laid the plans for the new organization and at both the immediate considerations and the far-reaching ideas which motivated them.

\section{Young Turkmanship: Nine Men and Their Motives}

Back in the days when the term could have been used with dignity and meaning, Dr. Meltzer was a true "organization man," one who was firmly convinced of the value of learned societies for the stimulation of creative thought and activity. In 1903, he had been instrumental in the founding of the Society for Experimental Biology and Medicine, popularly called the "Meltzer Verein"; in 1905, his enthusiastic support had urged the Harvey Society into existence (6). $\mathrm{He}$ is reported (7) to have overwhelmed the objections that such a society would never succeed in a city as lacking in scientific interests as New York by saying to the group of men assembled to discuss its possibility: "Never mind if no one comes except ourselves. We will wear our dress clothes, sit in the front row, and show the speaker that we appreciate him."

It must have been with the same ardent conviction that Dr. Meltzer inspired his companions on the Boardwalk with the idea of forming still another society, yet one which was not to be just another society. His views as to what it should represent were very positive ones and provided the foundations on which the young organization was built. Yet it is curious that Meltzer himself was not a member of the original four-man committee which took the first steps in transforming idea into action. In seeking the reason, another facet of his personality comes to light. Dr. Tileston (2) offers the following explanation:

Dr. Meltzer from the beginning decided to take no part in the organization of the Society but to leave that to the younger men. $\mathrm{He}$ was a modest man, and much older than the others, and he preferred to stay in the background. That accounts for the fact that he was not a member of the committee that met in Boston in 1907, and did not attend that meeting.

Dr. Meltzer was, in 1907, 56 years old and, in the words of Dr. Pratt (8), "took a fatherly interest in the young clinicians"-Longcope, then 30 years of age ; Christian, 31 ; Tileston, 32 ; Hew- lett, 33; Capps, Cole and Pratt, 35 ; and Edsall, 38. These young men were a diversified group in terms of interests, educational background, and the subsequent patterns of their professional careers. But all were representative of the type of man on whose shoulders Dr. Meltzer, addressing them as the Society's first president, was to place the responsibility for upholding "the science of clinical investigation." The concept of such a science was a radical one at the turn of the century. It was to become commonly accepted during the lifetime of the younger men. Changes beginning to be felt about 1900 were to make of medicine a strikingly different discipline from that which men of Dr. Meltzer's generation had known. There could be no more fitting illustration of some aspects of this changing picture than the professional career of Dr. Meltzer himself.

Samuel J. Meltzer. Born in Courland, Russia, in 1851 ; went, at an early age to Konigsberg and thence to Berlin to study medicine under "the best faculty in Europe"-Virchow, Leyden, Frerichs and Kronecker; turned down a position at the University of Berlin to come to the United States; made several trans-Atlantic trips as a ship's doctor until, in 1883, he had acquired the means to establish an office of his own in Harlem; built a large and lucrative practice; carried out physiological and pharmacological experiments in whatever spare hours he could find; in 1904, closed his offices to become head of the Department of Physiology and Pharmacology at the newly-established Rockefeller Institute for Medical Research; there, until his death in 1921, devoted himself to studies of major importance to medicine-the role of magnesium in the organism in health and disease; inhibition as a positive factor as opposed to excitability; anesthesia, especially intratrachial insufflation; the effects of epinephrine (9).

Dr. Meltzer was an extraordinary man: an avid reader of several languages; possessor of an extremely retentive memory; above all, wholly dedicated to the science of medicine.

Of his student days in Germany, we have the following rather amusing anecdote:

While working in Kronecker's laboratory, he (Meltzer) studied the mechanism for swallowing, which involved passing into his own stomach a double barrelled stomach tube. At this time, a bill was pending in the 
Reichstag for the abolition of animal experimentation. It claimed that doctors carried out on animals what they feared to do on themselves. The Minister of Health, while himself making a tour of inspection, entered the laboratory while Meltzer was recording notes with this ungainly tube in his stomach. The inspector requested its removal, asked about Meltzer's studies, and then used this episode for the defeat of the impending bill. $\mathrm{He}$ requested all members of the SPCA to submit themselves for study to Dr. Meltzer. None accepted his challenge (9).

After his sojourn in the German university clinics, Dr. Meltzer must have found the scientific atmosphere-or rather, the lack of it-in America rather stifling. During the post-Civil War decades, research-medical and otherwise-received virtually no support from either government or commercial sources and very little from private subsidy. The scientific studies of the French and German clinicians had made a slight impression on the native medical outlook, at least among the upper echelons of the profession, but medicine remained, by and large, a practical art based on "tried and true" remedies. There were only three or four medical centers in the country where the sciences were systematically pursued. Isolated individuals with pitifully inadequate equipment carried out such experiments as they could find time for in the daily routine of practice. Dr. Meltzer's experience was typical:

After visiting his patients, he (Meltzer) would drive to the physiological laboratory of the College of Physicians and Surgeons, tie his horse to a lamp post, and perform some physiological experiment. Many experiments were also carried out in his own little house, often late at night (6).

During the closing years of the century, however, a brighter future seemed imminent. The activities of men engaged in research, both here and abroad, began to emerge from the phase of mere classification and description of disease and to show promise of results which would contribute to progress in the prevention and cure of human illness-a development which was of particular importance if scientific medicine were to appeal to the practical-minded American public. At the same time, the period following the Civil War had been characterized by spectacular accumulation and concentration of wealth and individual fortunes had risen to previously undreamed of heights. The possessors of such wealth, who previously had been inclined to patronize religion or the arts, began to see in science something worthy of a second thought.

In 1867, Johns Hopkins, a Baltimore merchant and financier, decided to use his sizable fortune for the endowment of a university and hospital and, when he died in 1873 , he left $\$ 7$ million to be divided equally between the two (10). This was the largest individual gift bestowed upon a public institution up to that time. It was Hopkins' express command that the hospital should be of such high standards as to form, eventually, an integral part of the university medical school, a goal which was visionary indeed for a period in which most hospitals were conducted by local philanthropies or religious groups and most medical schools were in reality private businesses lacking anything resembling university standards. The hospital was opened in 1889; the medical school, in 1893. Hopkins' ideals were guided into reality by Daniel C. Gilman, first president of the university, and John Shaw Billings who planned and supervised the construction of the hospital and formulated principles for the development of a medical school which, with William Henry Welch as its first dean, was to become the exemplar for the vast improvements in American medical education which took place during the early decades of the twentieth century.

After Hopkins, the principle of private subsidy for science began to gain favor. The story of the founding of the Rockefeller Institute is no doubt a familiar one. In 1901, the Board received from the Rockefellers $\$ 20,000$ to be distributed as grants for medical research (11). The concept of providing funds to assist individuals during the course of investigations was, at that time, an innovation in striking contrast to the more usual practice of rewarding researchers, if at all, at the termination of their work. By using private wealth to stimulate the initiation of scientific studies, the Rockefeller grants set a precedent later followed by other philanthropists, the American Medical Association, private research councils and the federal government. The grants also served to gauge the country's readiness for the establishment of a permanent institute for research. The response indicated the existence of sufficient interest and personnel for such a venture, and in 1903 the grant program was terminated and a permanently endowed research laboratory built in New York. 
The following year, Dr. Meltzer, then 53 years old, joined the Institute's staff and embarked on the final stage of his career. It was a turning point for American medical research as well for, while it is unlikely that all investigators suddenly found themselves in possession of well-equipped laboratories and unlimited funds, it is certainly true that up-and-coming young men were no longer beset by the kinds of difficulties which had thwarted the research ambitions of men of Dr. Meltzer's generation. To them, instead, fell the tremendous challenge of putting their expanding opportunities to good use. This was to be no easy undertaking. It involved not only delving into the fundamental mysteries of health and disease, but attacking such corollary problems as the conversion of the medical profession to the view that these mysteries needed to be explored and could best be solved by the use of scientific techniques. Mobilization of the profession required, in turn, a drastic upgrading of the standards and methods of medical education. Among the men, fittingly designated "Young Turks," who dedicated themselves to these tasks there were: ${ }^{3}$

Joseph Almarin Capps (1872- ) who was born in Illinois and, after coming East for his medical training (M.D., Harvard, 1895) and internship (in several Boston hospitals), returned to his native Midwest in 1904 to become Assistant Professor of Medicine at Chicago's Rush Medical College. Between 1919 and 1926, he was Professor of Medicine there and, in 1926, assumed the position of Professor of Clinical Medicine at the University of Chicago. He was also Chief of Medical Services at Cook County Hospital. His principal scientific studies dealt with morphology of the blood, respiratory infections such as epidemic streptococcosis, physiology of the pleura, pain sense in the peritoneum and pericardium, and venous blood pressure.

Henry Asbury Christian (1876-1951), a Virginian who came North after receiving the M.D. degree from Johns Hopkins University in 1900 and soon thereafter began to make medical history

\footnotetext{
${ }^{3}$ In addition to references not specifically cited in the text, the following sources have been used, particularly for information regarding dates and professional positions, in compiling these biographies: History of the Interurban Clinical Club, 1905-1937 (12) and appropriate editions of Who's Who in America and American Men of Science.
}

in the city of Boston. His first positions were those of Assistant Pathologist at the Boston City Hospital and Instructor in Pathology at Harvard Medical School. In 1906, by this time Instructor in the Theory and Practice of Physic, he established a laboratory of experimental medicine at Harvard. In 1908, at the age of 32, he became Hersey Professor of the Theory and Practice of Physic (a position he held until 1939) as well as "the boy dean" of the Harvard Medical School (1908-1912) which was at that time undergoing revitalization at the hands of University President Charles W. Eliot. $\mathrm{He}$ and his colleague, Dr. Edsall, fathered the "Harvard full-time system" in clinical teaching (13). In 1910, Dr. Christian was appointed Physician-in-Chief of the new Peter Bent Brigham Hospital (opened in 1913) and was largely responsible for organizing and developing it as an outstanding teaching hospital of Harvard University (10). There he instituted a system of student clinical clerkships (Dr. Edsall was simultaneously doing the same at the Massachusetts General Hospital), a system which had been imported from Great Britain and put into effect under Dr. William Osler at Johns Hopkins, but which was otherwise an innovation in American medicine (13). The system was designed to give fourth-year medical students real responsibilities in the care of patients as members of a hospital ward team and, as such, it added a significant dimension to their medical training. At the Peter Bent Brigham Hospital, in 1913, Dr. Christian introduced the first electrocardiograph ever to be used in a general hospital in this country. He retired from active service as Physician-in-Chief in 1939. Three years later, he took on new duties as Clinical Professor of Medicine at Tufts Medical School and Visiting Physician to the Beth Israel Hospital of Boston.

Dr. Christian's published studies, on pathological and clinical subjects, dealt primarily with cardiovascular diseases, nephritis, diuretics and multiple myeloma.

Rufus Cole (1872- ) received the B.S. degree from the University of Michigan in 1896 and began his medical studies there. During one of his summer vacations, however, he visited the Chicago World's Fair and saw there an exhibit of the newly organized Johns Hopkins Medical School (14). Deeply impressed, particularly by 
the plans for the anatomical laboratory being developed under Dr. Mall, he arranged to transfer to Hopkins for his final year of medical studies, a feat of considerable difficulty since the faculty of medicine had shown great reluctance to admit students who had not, from the beginning, been imbued with the approach to the study of medicine then being developed in Baltimore. Following his graduation in 1899, he held, until 1909, positions at Hopkins ranging from Resident to Associate in Medicine. During these years he participated in important phases of Hopkins' transition into a research-centered institution comparable to the great German universities. $\mathrm{He}$ was put in charge of the biological research laboratory established in Dr. Lewellys F. Barker's clinic and there engaged in Hopkins' first systematic clinical research (10).

In 1908, Dr. Cole was offered the first directorship of the new Hospital of the Rockefeller Institute for Medical Research, "new" not only in terms of facilities but in terms of the idea for which it stood. ${ }^{4}$ After accepting the position, he spent several months abroad to acquaint himself with research activities in Europe, particularly those of the German university medical clinics. Although these were far in advance of anything in America, none completely embodied the vision which Dr. Cole and the Rockefeller Institute's Board of Scientific Directors hoped to realize in the Hospital (10). Thus, in formulating the plans for its construction and organization, Dr. Cole worked largely without precedent. $\mathrm{He}$ devoted nearly 30 years, until his retirement in 1938, to the development of this Hospital which itself became the prototype for medical research institutions all over the world. During these years, Dr. Cole continued his own scientific studies. His major interest was the field of infectious diseases and immunity, and his contributions, particularly with respect to lobar pneumonia, were outstanding ones.

David Linn Edsall (1869-1945) was among the young physicians who, about the turn of the century, experienced first-hand the contrast between the European and American medical research climates and who, upon returning from their studies abroad, began to do something

4 Dr. Cole's work both at Johns Hopkins and at the Rockefeller Hospital is discussed in greater detail below. about the medical backwardness of their own country. Edsall was graduated from the University of Pennsylvania with the degree of M.D. in 1893 and, following his internship, pursued his studies (in 1894-95 and in 1901) in London, Vienna, and Graz. Between 1895 and 1910, he held various positions at the University of Pennsylvania including those of Associate at the William Pepper Laboratory, Assistant Professor in Medicine, and Professor of Pharmacology and Therapeutics. During this period, he developed an interest in the medical problems of industry, contributing studies on the prevention of industrial disorders which evidenced his awareness of environment as an important factor in determining the complete clinical picture (15). This early interest in social aspects of medicine was carried over later in his career when in 1922 he became Dean of the Faculty of the Harvard School of Public Health.

His contributions to medical education were of particular significance. Although he spent only a single year at Washington University in St. Louis (as Professor of Preventive Medicine in 1911-12), many of his ideas were influential in the reorganization of that university's medical school which was taking place at that time (10). In 1912, he was appointed Jackson Professor of Medicine at Harvard and Chief of Medical Services at the Massachusetts General Hospital (the first non-Bostonian, incidentally, ever to hold these positions simultaneously). Thereafter, he worked with Dr. Christian in bringing the fulltime system into being at Harvard, first, by picking a group of interns from Massachusetts General Hospital and preparing them for his full-time staff by sending them abroad or to research laboratories in this country for experience in the methods of investigation; then, by transforming administrative offices into research laboratories, raising funds for equipment and salaries and, finally, putting his teaching staff to work on various lines of clinical investigation (13).

In 1918, he was appointed Dean of the Harvard Faculty of Medicine (until 1923, he held this position simultaneously with his professorship) and, in 1922, Dean of the Faculty of the School of Public Health, posts at which he remained until his retirement in 1935. His own major field of investigation was concerned with metabolic disturbances. 
Albion Walter Hewlett (1874-1925) was a native Californian who came East as a member of the fourth class to enter the Johns Hopkins Medical School from which he was graduated with the M.D. degree in 1900. He returned to San Francisco for two years as Assistant Professor of Medicine at Cooper Medical College (1906-08), then became Professor of Internal Medicine at the University of Michigan (1908-16) and returned once again to the West Coast to become Professor of Medicine at Stanford University until his death in 1925. His scientific studies dealt with irregularities of the heart, the blood flow in the arm, and other subjects in the field of pathological physiology.

Warfield Theobald Longcope (1877-1953) exemplified the type of teacher of medicine who was to come into increasing prominence during the first decades of the Society's existence-the teacher whose primary interest was research rather than practice. Except for part of one year when he entered practice in New York City, Dr. Longcope devoted himself to teaching and investigation and limited his direct contact with patients to that connected with his responsibilities in university-affiliated clinics (10). He was a modest, unassuming man who, in his teaching, took a deep interest in his junior associates and communicated to many of them not only his great wealth of knowledge about disease but his enthusiasm for the study of medicine (16).

Longcope was graduated from Johns Hopkins with the M.D. degree in 1901 and, as Resident Pathologist (1901-03) and Director of the Ayer Clinical Laboratory (1904-1910) at the Pennsylvania Hospital, he pursued the studies in bacteriology and pathology which had caught his interest during his student days. There he began the investigation of antigen-antibody mechanisms which were of abiding interest to him throughout his career (16). In 1911, he left his position as Assistant Professor of Applied Medicine at the University of Pennsylvania for an associate professorship in Columbia University's department of medicine. In 1914, he succeeded his chief, Dr. Theodore C. Janeway, as Bard Professor of Medicine and Director of Medical Service at the Presbyterian Hospital. He held both posts until 1921. In mid-1922, he became Professor of Medicine and Physician-in-Chief at Johns Hopkins and there undertook a series of important investigations on hemorrhagic nephritis. During the Second World War, despite his 65 years of age and the additional teaching burdens which devolved upon him in the wartime absence of many of the younger staff members, he managed to supervise and participate in a series of studies on the effect of British AntiLewisite (16).

That Dr. Longcope was a life-long student of medicine is in part attested to by the fact that throughout his career he maintained up-to-date files on his "favorite" diseases-syphilitic aortitis, infectious mononucleosis, Hodgkin's disease, serum disease, hemorrhagic nephritis, virus pneumonia, and sarcoidosis-which contained reprints, case notes, miscellaneous clippings, photographs and personal observations. To these files he continued to add right up to the last weeks of his life (16).

Joseph Hersey Pratt (1872-1956), another Hopkins graduate in medicine (1898), also had opportunities to pursue his studies in the German universities, working under Krehl in 1902 at Tübingen and in 1908 at Heidelberg. Meanwhile, following his graduation from Hopkins, he began his professional career in Boston. His first positions were residencies in pathology at several of that city's hospitals; Instructor in Pathology at the Harvard Medical School ; and, later, Assistant (1902-09) and Instructor (1909-17) in Medicine at Harvard and Visiting Physician to the OutPatient Department at Massachusetts General Hospital (1903-13).

During this period, he became interested in tuberculosis. Finding it difficult to meet each of his clinic patients individually, he organized, in 1905, weekly classes for group instruction in the treatment of tuberculosis with such sidelights as prizes for those who had accumulated the most hours out-of-doors or gained the most weight (17). The innovation proved to be both popular and effective and 25 years later, as Physician-in-Chief at the Boston Dispensary (1927-31), Dr. Pratt extended the ideas inherent in these classes to the area of group therapy for emotionally disturbed patients. His "Thought Control Classes," designed to provide mutual encouragement and stimulation to such patients, were pioneer ventures in the field of group psychotherapy (17).

In 1929, Dr. Pratt became Professor of Clinical Medicine at Tufts Medical School and two years later, Physician-in-Chief of the New England 
Medical Center which was created through the affiliation of the Boston Dispensary, Tufts Medical School, and the Floating Hospital for Children. Another of his outstanding accomplishments involved the dissemination of medical knowledge and the promotion of better medical care among New England practitioners (17). In 1930, he spent several weeks caring for a wealthy gentlemen named William Bingham, 2nd, who thereafter provided the financial backing for a program organized by Dr. Pratt and designed, in particular, to assist local physicians in the diagnosis of puzzling cases before referring them back for treatment. In 1937, on Dr. Pratt's sixty-fifth birthday, the cornerstone of the Diagnostic Hospital which bears his name was laid. Later, a surgical unit, a medical research laboratory and other buildings were added, all through the generosity of the "Bingham Associates." In the meantime, Dr. Pratt organized a program whereby family doctors were invited to spend a period of time in Boston observing and participating in the work of the Medical Center, and another in which able medical students were encouraged to spend a kind of "apprenticeship" as assistants to local physicians (17). These programs, as well as the "Thought Control Classes," have continued in effective use and are today a testimonial to Dr. Pratt's remarkable leadership and teaching abilities.

Wilder Tileston (1875- ) did both his graduate and undergraduate work at Harvard, receiving the M.D. degree in 1899 . He served his internship at the Massachusetts General Hospital and then held teaching positions at Harvard in Clinical Chemistry, Clinical Medicine, and Pathology until 1909. In that year, he went to New Haven to become Assistant Professor of Medicine at the Yale University Medical School, a position which he held until 1919 when he was advanced to the post of Professor of Clinical Medicine (1919-20). Subsequently he became Clinical Professor of Medicine. During these years he also held positions in several hospitals in New Haven and nearby towns.

These, then, are the nine men who directed the Society's debut. We have already gained some insight into the nature of the concerns which might have prompted them to take part in the new venture, but there is undoubtedly more to be discovered about their motivation. Why, we may legitimately wonder, did they agree that a new society was needed? What were the slightly "different aims" and "different membership" they envisioned? What was the nature of their apparent dissatisfaction with those societies "already in existence"?

It is evident from many of the recollections included in the preceding section that a major stimulus to the Society's birth was the fact that the well-established Association of American Physicians could not accommodate the rapidly increasing number of young men eagerly awaiting an opportunity to present their work before that much-respected body of elders. These young physicians no doubt attended the AAP meetings just as today much larger crowds flock to Atlantic City to listen to the scientific sessions of the Association, the Society, and the still younger American Federation for Clinical Research. Although the records of the Association do not attest to the fact, it is quite probable that the impetus for the formation of the Society came, at least informally, from within the AAP itself. Of the nine member committee which laid the plans for the Society's charter meeting, five-Drs. Capps, Christian, Edsall, Meltzer and Pratt-were at the time members or associate members of the AAP. While there was never any formal affiliation between the two societies, the founding of the Young Turks certainly had the dual effect of alleviating pressure for expansion on the Association and of providing a forum for its youthful disciples.

The Association's membership, in 1908, comprised largely the outstanding consulting internists of the day, most of them part-time professors as well as practitioners. A few men representing the basic sciences had been included to enable the physicians to keep abreast of developments in related fields. All were distinguished, top-ranking men.

Were they, perhaps, too distinguished? This is a view expressed by some Society members in accounting for the "revolt" of the Young Turks. The Association, they contend, had become a "very conservative and somewhat dull society, unaware of the tremendous advances being made in medicine." Its members were somewhat "set in their ways"-eminent men without a doubt, but "not very scientific." The new society was formed as a "protest" against these distinguished "stiff shirts." It consisted of "rebels and roughnecks" 
who wanted a meeting wherein they could "get up and report real experimental results, not case histories."

These judgments represent a rather extreme point of view, and it should be noted that they constitute a hand-me-down version of the story. ${ }^{5}$ Although it undoubtedly contains elements of truth, the degree of disesteem for their elders imputed to the first-generation Young Turks has probably been considerably exaggerated with the passage of time. Dr. J. Howard Means, the Association's official historian, does not believe that that organization's programs could legitimately be called "too stuffy and stale" during the years immediately preceding the Society's formation. Although the titles were generally broad enough so that any member was qualified to discuss any paper and the programs usually very clinical, Dr. Means points also to the fact that the older physicians were eager to keep in touch with the allied sciences and to maintain an up-to-date point of view.

The proper balance is probably struck by $\mathrm{Dr}$. Cole (18) in the following account:

I was much interested in the AAP to which I was elected when I was very young, and I had attended the meetings in Washington when I was still a student and intern in Baltimore. ... I know that some of the members, especially Dr. Meltzer and some of the younger members, felt that the papers were not scientific enough, and some of the older members complained that they were too technical. ... The limited membership of the Association made it impossible to elect all the younger men who manifestly deserved to belong. But I cannot recall that there were any acrimonious feelings or any spirit of rivalry exhibited.

The testimony of other charter members (2, 19) bears out the fact that the "insurrection" of the Young Turks was entirely good-natured. The new Society was formed not so much in protest against the old as in response to the needs of a younger generation which was beginning to use methods unfamiliar to its elders. Although the Society's organization, its structure, even the wording of its constitution reveal a hereditary relationship with the Association, the new organization at the outset exhibited distinct tendencies

5 The foregoing paragraph is a composite of statements made by several men who were elected to membership in the Society in the mid-1920's and whose information was based on what they had been told by older colleagues. to depart from the ways of its parent. The following excerpt from a letter written by Dr. G. Canby Robinson (5), who was elected to the Society in 1911, suggests the difference in emphasis and outlook which was to mark the younger group:

The idea of the Society was to bring together the men in the various clinics which were just being organized on a university basis and who were beginning to develop systematic research. It was a young crowd and was to be confined to the men who were active in clinical investigation rather than men who had become eminent in medical practice and teaching. The original idea was, I think, to have a one-day session of the acutal investigators the day before the AAP met, a plan that has been carried on to the present time.

Thus, in part, the difference was simply one of age-the Society was to provide a forum for young men whose time was still primarily devoted to research, whose energies had not yet been diverted into practice and teaching. In addition, however, Dr. Robinson notes that many of these young men were associated with the newly organized university clinics, As such, they were at the forefront of a far-reaching reform movement in medicine, a movement involving what Dr. Robinson (10) has characterized as "the intrusion of science into clinical medicine."

Significant components of this new outlook were the beliefs that clinical medicine was a science in its own right, that the investigation of disease was the legitimate concern of the clinician, and that the work of clinic and laboratory-of physician and basic scientist-ought to be more closely integrated and, in fact, combined in the person of an essentially new type of medical worker, the clinical investigator. Such beliefs had a number of important implications. The cultivation of a "research atmosphere" in medical schools and hospitals necessitated first, professors of medicine able to devote full time to research and teaching without the distraction of an extensive private practice; second, students and staff members trained in the methods and imbued with the spirit of science; and third, adequate laboratory facilities available to clinicians for the systematic study of clinical problems.

The realization of such conditions became the rallying cry of the new Society, but the reforms envisioned by its members were not to be instituted without a struggle. As partakers of the crusading spirit, the youthful Society members were very early designated "Young Turks" after 
the "real" Young Turks who in 1908 startled the world with a revolt against Sultan Abdul Hamid II, deposed him the following year and, with nationalistic fervor, set about to establish a constitutional regime and institute sweeping reforms in the decrepit Ottoman Empire (20). Newspapers in 1908 headlined the visionary, albeit impracticable, tactics of these "young men in a hurry" as they were called, and someone drew the parallel between the Turkish revolutionaries and their counterparts in American medical circles.

The concepts for which the Young Turks stood were not widely accepted in 1908. In academic medical circles there existed a definite schism between the basic scientist and the clinician (21). The divergence between the two and the direction of change which was to heal the rift, is illuminated in the following passage by Dr. Means (13), in which he describes the situation at Harvard University where he began his own medical training in 1907 :

The transition from the preclinical to the clinical years (third and fourth) in medical school involved almost as great a change in direction as that from college to professional school. The teachers of the first- and secondyear subjects and those of the third- and fourth-year subjects constituted two distinct groups with quite different viewpoints, and there was limited communication between them. The clinicians brushed off the preclinical scientists as mere laboratory men who knew but little of medicine, and the scientists looked upon the practice of medicine as largely unscientific guesswork. The whole manner of life of these two groups was different. The preclinical scientists were in the mold of college teachers on campus. They were full-time salaried people. There were no full-time clinical teachers in those days-or salaries either, for that matter. Small token honoraria were given by the university but nothing by the teaching hospitals. These men taught and attended hospital patients for love or kudos, or a mixture of the two, and made their livelihoods in private practice. Any degree of unanimity in a faculty so constituted I am sure was hard to come by. This gap was ... later to be closed by the development of the "middle estate" in medicinenamely the full-time academic, salaried clinician.

The development of this "middle estate" in medicine, which was to take place largely during the first decades of the Society's existence and to be an important part of the lives of many of its members, called for a new type of clinical teacher -one who was research-oriented rather than practice-oriented (10). Essentially, the difference between the two was the difference between the German and British schools of medical teaching. At the time the Society was founded, the predomi- nating medical influence in America was British as represented, for example, by Dr. William Osler, Professor of Medicine at Johns Hopkins University until 1905 . It was to the British school, too, that the majority of the established "elders" of the American Association of Physicians, who combined teaching with practice, belonged. Many of the members of the younger generation, however, were strongly influenced by the medical traditions of Germany. Some of them had been fortunate enough to study at the university clinics of that country where medicine enjoyed a status equal to that of the other sciences, where its teachers devoted most of their time to instruction and investigation, and where research flourished. It was in this direction that the reformers of American medical education hoped to move and it was this tradition, with its emphasis on research in academic clinical medicine, which counted as a significant motivating factor in the founding of the Society (22). The German influence is particularly apparent in such men as Dr. Meltzer, Dr. Cole and Dr. Lewellys F. Barker who was elected to the Society in 1914 and who, in 1905, had succeeded Osler as Professor of Medicine at Hopkins. The difference between the older tradition in clinical teaching and the German-influenced ideas which were beginning to challenge it can perhaps be most clearly illustrated by a brief comparison of the Hopkins department of medicine under Osler and under Barker $(10,14,22)$.

Osler was first and foremost an eminent physician and this fact was reflected in his conception of the aims of medical education and the role of the professor of medicine. Major emphasis was placed on imparting to students the techniques and skills necessary for observing and interpreting the manifestations of disease in patients; little on the investigation of underlying disease precesses. As Dr. Arthur Bloomfield (22) has put it: "Osler, I have been told, felt strongly that those things which are Caesar's should be rendered unto Caesar. In other words, laboratory work should be done in the pathological and physiological laboratories and not in the medical clinics by clinicians." Dr. Cole, who completed his medical training at Hopkins in 1899 and served under both Osler and Barker as Resident Physician, has described this attitude further (14):

... (U)nder Dr. Osler the opportunities for careful observation were never better and the importance of 
careful study of the more superficial aspects of disease never more insisted upon. But there existed in the clinic no great incentive to learn more about the fundamental nature of disease, and facilities for making the necessary investigation were lacking. The belief was general that medicine was basically different from biology or chemistry or anatomy and could only be studied by different methods. From time to time doubts about this point of view were expressed, but chiefly by workers in the underlying sciences and they usually held the opinion that the real investigations must be carried out by workers in their laboratories, since clinicians neither had the necessary time nor did they have the adequate training for these more complicated researches.

Dr. Barker, on the other hand, held that a primary function of the university department of medicine should be the encouragement of research and, accordingly, that the professor of medicine should be freed from the burdens of a private practice and allowed to devote his time to his own investigations and those of his staff (10). Although Barker's request that he be permitted to accept the professorship on a full-time basis was denied, he took important steps in the direction of organizing the department along research-centered lines. Shortly after coming to Hopkins, he established laboratories in his clinic for investigation in the fields of biology, chemistry and physiology and added to his staff clinicians with training in these areas. These clinical research laboratories differed radically, both in scope and in purpose, from the usual hospital laboratory which existed primarily for diagnostic and teaching purposes and for such routine work as the analysis of bloods and urines $(10,22)$. The new laboratories were designed to provide the clinician with the opportunity and the facilities for more fundamental study of the problems which confronted him on the wards. Dr. Cole was put in charge of developing the first of these research laboratories, that devoted to biological studies, and in it he began immediately to carry out investigations of typhoid fever which not only contributed significantly to an understanding of the nature of that disease (10), but which stood as indisputable evidence to the thesis that the scientific experimental method could successfully be applied by clinicians to the study of clinical problems. When, in 1908, Dr. Cole was asked to become the first Director of the Hospital of the Rockefeller Institute, he acquired a unique opportunity to give concrete expression to this point of view. In formulating plans for the new Hospital, he was insistent on the importance of building the wards in close proximity to the Institute laboratories and of including on his staff men who could bring their knowledge of the basic sciences to bear on clinical problems. His views on this subject, in striking contrast to those of Osler, are summarized by Dr. Robinson (10) as follows:

It was his (Cole's) opinion that the physical and intellectual barrier between the laboratory and wards then existing in many hospitals had seriously delayed the advancement of medicine in this country; he urged that the hospital be developed as a true research laboratory and expressed the fullest sympathy with the closest possible connection between the institute laboratories and the hospital. This relationship represented new and favorable conditions for the development of clinical medicine as a science.

Closely related to this new conception of clinical medicine was the question of the type of training appropriate to the aspiring clinical scientist, a point on which Dr. Meltzer had particularly strong convictions. It was his belief that training in one of the allied sciences of medicine, with extensive work in the laboratory, was as essential to the development of a top-notch clinician as was his training on the wards. That he differed from the majority of his contemporaries in this. respect is brought out by Dr. Pratt (8) :

Many of the older clinicians seemed to think it was a foolish thing for a young man who expected to become a clinician to engage in physiological or chemical studies in the laboratory, whether the observations were on patients or on animals. Dr. Meltzer thought it very important to encourage and assist young clinicians who were carrying on investigative work, especially in the laboratory, during their early years.

Dr. Meltzer was to stress this belief, and the broader attitude of which it was a part, when he addressed the Society as its first president. In his talk, entitled "The Science of Clinical Medicine: What it Ought To Be and the Men To Uphold It" (23), he directed attention to the shortcomings of investigative medicine in this country, outlined a vigorous campaign for its betterment, and exhorted his listeners to dedicate themselves to the struggle which lay ahead. The influence of the German tradition on the Society's ideals is clearly apparent in his statement. There could be no more appropriate summary of the considerations which gave rise to the Society's birth and the concerns that were to shape its future than the words of its founder and first president. Dr. Meltzer's address is herewith reprinted in full. 


\section{THE SCIENCE OF CLINICAL MEDICINE}

WHAT IT OUGHT TO BE AND THE MEN TO UPHOLD IT

By SAMUEL J. MELTZER

The honor of the presidency of a society goes with the privilege of discussing some of the aims of that society. Such a privilege becomes a duty on the occasion of its first birthday. We have to show the specificity of our objects to justify the addition of a new medical society to the many already in existence. As your first president and as one of the instigators of the movement which led to the formation of this association permit me to discuss some of the problems to the solution of which this association wishes and hopes to contribute.

\section{CLINICAL MEDICINE AS A SCIENCE}

In the first place, I wish to discuss the problem of clinical medicine as a science. In years gone by, medicine was a unit and its leaders tried to master all its aspects. With the development of scientific methods and the growth of knowledge a process of differentiation took place. Heavy branches grew out of the stem of medicine, broke off and obtained an independent existence. Anatomy with all its dependencies broke away early, then followed physiology, pathologic anatomy, pharmacology and physiologic chemistry. Bacteriology tore off the branches of etiology and established itself as an independent growth. All these offsprings of medicine are now well established as pure sciences; they still closely affiliate with the mother-stem and are often designated as the sciences of medicine. That what is left of the old stem is clinical medicine. What is the character of this residuum? It is generally designated as the practice of medicine. I am not aware that any one has had the courage to call it a pure science. Those who do not like to call it an art say that it is an applied science. According to this view, the relation of clinical medicine to the sciences of medicine is that of technology to science in general. I am afraid that this conception of clinical medicine is widespread among those who are in the practice as well as among those who are in the sciences of medicine.

However this may be, I feel sure that such a view is logically erroneous and practically harmful. I wish to plead for an extension of the process of differentiation also to clinical medicine. I am of the opinion that clinical medicine as it exists now is made up of two constituents : one part has all the elements of a pure science and ought to be coordinate to the other pure sciences of medicine, and the other part is the real practice of medicine, an applied science which has many elements of an art. At present both parts are so closely interwoven that they present the appearance of a natural unit the splitting of which into two parts might appear to some as an impossible and undesirable process. I shall call to mind, however, that medicine made the same impression of an indivisible unit in the days when pathologic anatomy, physiology, etc., were inseparable constituents. To-day nobody doubts the necessity of an independent existence for the last-named constituents of former medicine. A considerable degree of separation of the science of clinical medicine from its practice is more desirable than even the separation of the coordinate sciences, because the requirements of sciences and practice are in a certain sense mutually antagonistic to one another and the simultaneous cultivation of both branches with equal attention is detrimental to the progress of either of them.

There is a fundamental difference between science and its correlated practice in 
any sphere of human activity. Science wishes to attain truthful knowledge of the subject it investigates. It attains this end in the safest way when it is least sidetracked by any extraneous motives. The motive of utility obscures its vision, and haste retards its progress. Practice, on the other hand, avails itself of acquired knowledge for the purpose of attaining a certain useful end. The more reliable that knowledge is which it has to employ, the more safely will it attain that end. But the use of any part of that knowledge which is indifferent to the attainment of the useful end hampers the practical progress. In other words, practice gains its ends best the purer the quality and the smaller the quantity of the science which it has to use. Permit me to say that my advocacy of the separation of a clinical science from its practice is not actuated by any disregard for the practice of medicine. On the contrary, I entertain now and have always entertained a strong conviction that the efficiency of practice should be the supreme object in medicine. At the same time I feel sure that the efficiency of that practice will be best attained when the search for the knowledge which the practice has to use should be carried on in the same manner and by the same methods as are employed in the search for knowledge in other branches of intellectual activity. In other words, clinical research should be raised to a department of a clinical science and be theoretically and practically separated to a considerable degree from the mere practical interests, that is, separated so far as the various and variable conditions permit. It will be the practice not less than the science of medicine which will benefit by such a separation.

Now let us see what the domain of clinical medicine is and whether it contains problems which can be treated by the methods employed in pure science. The sciences of normal anatomy and physiology teach us the structures and functions of the normal body; pathologic anatomy tells us of the anatomic changes found in a body dead from one disease or another. To clinical medicine is left the study of the phenomena and their sequence as they occur in a living body during the entire course of a disease. It has to interpret these phenomena by known physiologic laws, to identify them with similar phenomena experimentally produced in animals and it has to correlate the phenomena observed in the course of a certain disease during life with the anatomic changes found at the postmortem examinations in case the disease has a fatal termination. It is also one of the tasks of clinical medicine to study the influence on the onset and course of phenomena of diseases which certain means and remedies may exert whose physiologic actions are well established. In other words, the domain of clinical research comprises the study of the natural history of diseases, their physiology and their pharmacology. Can there be any doubt that these studies constitute legitimate objects of a pure science? Objections may be raised, and will be raised in certain quarters, against the admission of the clinical science to the sacred inner circle of pure sciences on account of the impossibility in clinical medicine to verify the conclusions by the experimental methods. Assuming that this is an unassailable fact, what of it? Are the problems of biology, a science which enjoys an unassailable position in the councils of pure sciences, all or many of them provable by experiment? Or are the sciences of paleontology or geology amenable to an experimental proof? Yet nobody questions the scientific right of these branches of human knowledge. Furthermore, admitting that clinical research must necessarily remain less precise and its results less convincing than that, for instance, of physiology. But, then, physiology itself is again a great deal less precise than physics and chemistry and is certainly less irrefutable than anatomy. Does this throw a doubt on the claim of physiology to be a pure science? 
As to the impossibility of verifying certain conclusions regarding human diseases by human experimentation, there is still this much to say. Each disease is an experiment which Nature makes on the organism. The very large number and the great variations of these experiments of Nature offer favorable opportunities for testing the theories made regarding the nature of these spontaneous experiments. Furthermore, clinical research should, indeed, be coupled with animal experimentation; any new point of view gained by observation in clinical medicine which cannot be verified on human beings should be tested by experiments on animals. By such a procedure not only clinical medicine, but also physiology may learn a good deal, for which the following facts from the recent history of medicine are classical illustrations. The recognition of myxedema as a special type of disease led to the understanding of the function of the thyroid glands, and the observation of the coincidence of pathologic processes of the pancreas with diabetes led to the discovery by clinical investigators of the glycolytic function of the pancreas. Finally, it should be borne in mind that there are lines of experimentation which may be carried out even on the sick human being without any detriment to him and which can be conducted with profit only by trained scientific observers, for instance some studies in pharmacology or in metabolism.

Among the tasks of clinical medicine there is one which is on the borderland between the science and practice of medicine, being perhaps of greater importance to the latter than to the former. It is the search for simple or complicated means by which established units of diseases may be recognized safely and perhaps also easily. In one word, it is diagnosis. Since this activity is not carried on with a purpose of adding knowledge, it would appear that it belongs rather to the department of the practice of medicine. Such facts can be established only by means of careful critical observations and it will be more to the purpose when at least the development of the principles of diagnosis should remain in the hands trained in careful methods of research.

After showing that there is a definite field for a science of clinical medicine the next question is who should be the men to carry on the research in this field, what should be their qualifications? In the first place, they must have a training fitting them to carry out investigations in conformity with the requirements existing in all pure sciences. They must not only be informed and trained in the other sciences of medicine, but must have carried on various investigations in one or more of these pure sciences, so as to become familiar with careful scientific methods and imbued with a scientific spirit. They will thus learn best how to shape a problem so as to make it amenable to a solution; how to marshall the consecutive steps of an investigation so as to bring out the reply to the question in hand. They will learn to avoid bias in the search, to apply criticism to the findings; they will learn not to trust only few facts, not to rejoice prematurely over findings and not to be disheartened by failures. They will thus acquire the habits and the tastes of the investigator, the scientist, which may then stick to them for life.

However, after all these preparations they must select clinical research as the main field of their scientific activity. Clinical science will not thrive through chance investigations by friendly neighbors from the adjoining practical and scientific domains. Such volunteer service which for the present is keeping up the cultivation of the unacclaimed region is most certainly very welcome. But the acclamation, cultivation and maintenance of a field of pure science of clinical medicine cannot be accomplished by chance services from volunteers; for such a purpose we need the 
service of a standing army of regulars. The investigator in clinical science must devote the best part of his time and intellectual energies to the cultivation and elevation of this field just as the physiologist does in his domain-or at least as he ought to do. For the sake of elucidation let us compare the relations of a science of clinical medicine to its practice with the relations of science to technology in any part of physics or chemistry. Let us take electricity as an instance. In the electrical industry there is a large corps of electrical engineers who are bright, inventive and on the alert to make practical use of any newly discovered principle in general. Some practical engineers manage to make valuable contributions to the theoretical knowledge of their branch. Nevertheless the science of electricity is in the hands of pure scientists who are setting the pace of progress in the correlated practical branch. It is the discovery in pure science which makes great inventions possible. It was, for instance, the purely scientific demonstration by Hertz of the existence of electric waves that gave the impetus to and made the invention of wireless telegraphy possible. The following is a quotation from the presidential address of Professor Nichols before the Association for Advancement of Science: ${ }^{1}$ "Communities having the most thorough fundamental knowledge of pure science will show the greatest output of really practical inventions." This is surely true also for medicine. And let me say to you that the Hertz's, the Roentgens, the Bunsens, the Emil Fischers, and a host of others, who are the real creators of knowledge and invention, are satisfied to live on comparatively small salaries, while it is within their easy reach to make twenty times the amount of their salaries as consultants, if they would be willing to give up a part of their time which they devote to investigations in pure science. Now, the leaders in practical engineering in electricity surely compare favorably with the leaders in the practice of medicine with regard to the completeness of their knowledge in the respective spheres. While thus the search for knowledge in electricity is carried on by men devoting themselves to pure science, the search for knowledge in clinical medicine is left in the hands of men who devote most of their time and energies to their practice and to the golden fruit it bears. Under such circumstances, how shall we expect to find the progress in science and practice of medicine keeping abreast with the striking progress to be met within other branches of science and practice?

A few years ago I tried to fix the responsibility for the shortcoming of internal medicine in physiology, because this science is keeping aloof from medicine and its problems. $^{2}$ Anatomy, which gave its undivided attention to the human structures, prepared an excellent basis for a successful surgery, the problems of which are essentially mechanical in character. The problems of clinical medicine are essentially of a functional character, and the enlightenment which it requires must come from physiology. This science, however, developed a tendency to keep at a distance from medicine on account of the inexactness of the latter. There is an improvement to be noted in this regard; there is a growing tendency in physiology nowadays to pay greater attention to medical problems. However, even if physiology and other related medical sciences would devote all their time and energy to the study of purely medical problems, it would not bring about a radical solution of our perplexing problem. Neither will this be accomplished by the creation of chairs for experimental medicine. The regeneration or rather creation of a science of clinical medicine must come from the innermost of medicine itself. It is true, as stated

\footnotetext{
${ }^{1}$ Science, Jan. 1, 1909, p. 5.

2 Congress of Science and Art, 1904, v. 395 ; chairman's address.
} 
before, that the men who are to tackle these problems must have a thorough training in the sciences allied to medicine, but the center of their activities must be within clinical medicine itself. They must have a bringing up within medicine, their minds must have been filled up with thinking, worrying, brooding over practical and theoretical problems of clinical medicine.

Let me recapitulate. There is a necessity for a differentiation of clinical medicine into a science and a practice. The clinical science has well-defined objects and is a most important department. It must be managed by a set of men specially trained for and almost exclusively devoted to that task. Without the development of such a department of clinical science the efficiency of the practice of internal medicine will lag behind, no matter how progressive the allied sciences of medicine are and how great their efforts to be useful to medicine may be.

\section{THE CONDITIONS AS THEY ACTUALLY EXIST}

In conjunction with the foregoing considerations let me glance at the conditions of clinical medicine as they actually exist here and abroad. I may state that neither abroad nor here do we find a separate class of investigators confining their activity solely to the domain of the science of clinical medicine. Everywhere science and practice of clinical medicine go hand in hand. We may, however, admit at the outset that there is an enormous difference in the status of medical research between abroad and here. Let us take the development and the present status of clinical medicine of the German-speaking countries as an illustration of the conditions abroad. We shall notice that there the mother stem of medicine managed to retain a scientific aspect despite all processes of differentiation.

When for the first time pathologic anatomy broke away completely from medicine and was taught by Rokitansky at the University of Vienna as an independent branch of medical science, we find that at the same time and at the same place the celebrated Skoda was teaching the remaining trunk of clinical medicine as a natural science, constructing the methods of auscultation and percussion on a sound basis and establishing a firm connection between the intravitam diagnosis and the postmortem findings. The purely anatomic tendencies of that celebrated school of medicine which unfortunately gave birth to nihilism in medicine, was soon curbed by the appearance of Virchow on the medical scene in Berlin. While also working for the establishment of pathologic anatomy, gross and histologic, as an independent natural science, he manifested throughout his long life a deep interest in the development of clinical medicine on sound lines. At the very beginning of his brilliant career we find him stating (in the prospectus to the first volume of his Archiv) that practice of medicine should be an applied science and the ideal of the science should be a complete pathologic physiology. The great clinical contemporaries of Virchow strove for a similar ideal. Frerichs introduced chemistry and Ludwig Traube the methods of experimental physiology into the domain of clinical medicine. I shall not dwell here further on historical details. I shall only say that clinical medicine in Germany remained true to this ideal throughout all these years of marvelous growth of medicine. The exponents of clinical medicine in Germany are the flag bearers of pathologic physiology. The contemporary clinicians master the immense knowledge and manual skill which contemporary clinical medicine demands of its disciples, and nearly all of them are themselves diligently adding new facts to the store of medical science. I do not need to tell you the particulars. Some of you know from personal experience such master clinicians like Müller, Krehl, Kraus, 
Minkowsky, and a good many others like them. However, the standard of medicine is kept high not only by the heads of university clinics; the various members of their staffs, heads of hospitals and their staffs and a host of volunteer workers are continually digging for new fruit in the soil of clinical medicine. The medical literature is full of original, first-rate work in the science of clinical as well as of experimental medicine contributed by men whose main abode is clinical medicine.

Now there is in Germany no special chair for the science of clinical or even experimental medicine. All these contributors to medical science are in a sense simply medical practitioners. What is the secret of their scientific success? It is simply this: to these men science is the first and practice the second object of their life. To most of the leaders of medicine in Germany the tasks of gaining and diffusing knowledge receives their first attention and the consultation practice comes in last. Again, these very leaders before they have acquired their commanding positions spent many years of their life in preparing themselves for it; in training in scientific methods, in acquiring knowledge in the allied sciences and in the science and practice of clinical medicine, living meanwhile on small incomes, having no private practice at all or having a practice too small to interfere with their life ambition. You cannot lead such a life unless you are possessed by idealism and a scientific spirit. That is the key to their success. And when these men become teachers, they cannot fail to impart this ideal spirit to their students. That is the way they themselves received it. But they received it also in the institutions of their early education, where sport and habits of millionaires' sons are not the factors which form the character of the youth. They received it from the people among whom they grew up, among whom the worth of the individual is not measured exclusively by a gold standard. They received it from the care and encouragement of the government which, no matter what its political ideals may be, never loses sight of the fact that the cultivation of science is one of the greatest assets of a people. They received it in the traditions of medicine of their country; even before the new era when medicine was all in a cloud of so-called natural philosophy, only the substance of medicine was all wrong, its spirit was all right.

That is the situation abroad. Now let us look at the development and the present status of clinical medicine in this country. At a glance one observes with amazement that nearly all the factors which favored the development of a scientific spirit in Germany are absent. However, I shall not try to enumerate all the shortcomings with which the development of medicine in this country had and still has to contend. There is no educational advantage in doing it and you are all familiar with the situation. On the contrary, I take pleasure in pointing out the encouraging fact that, despite all the difficulties, medicine in this country gradually rose to a commanding position in many respects. It is an instructive and stimulating fact that the progress of medicine in this country was carried on through the efforts of a few high-minded men or groups of men who at various times transplanted the spirit prevailing abroad into this country. I shall, of course, not attempt to enter into the particulars of the history of this progress. I wish to refer briefly, however, to a few phases in this history. In the first important phase, clinical medicine in America received an elevating impulse through the activities of a group of medical men who continued their studies in France, where they came especially under the influence of the famous clinician Louis. Statistical methods of observation of diseases and diagnosis by auscultation and percussion became, then, the chief characteristics of internal medicine in this country. During the second period, young 
American physicians pursued their postgraduate studies in Austria and Germany. They brought home a knowledge of gross and minute pathologic anatomy and an aptitude for the use of the microscope. Pathologic societies were started and the teachers of medicine began to give separate lectures on pathologic anatomy and to instruct in the use of the microscope as a clinical aid. The studies and teaching of these new subjects gave at that time a scientific flavor to clinical medicine. The last period covers about the three last decades with the contradictory results of which we are confronted to-day. Again, 'medical men went abroad for postgraduate studies and perhaps in larger numbers than ever. But what this high class of young medical men studied there now was no longer in the direct interest of clinical medicine; they trained themselves in the intricacies of the sciences of medicine. The results of the studies of this period were again of great benefit to medicine in this country; in fact, they were of greater benefit than ever. In a comparatively short period the special sciences of medicine, thanks to the activity of a brilliant group of men, have gained a strong foothold in this country; special chairs and laboratories were created in many schools of medicine for pathology, physiology, bacteriology, pharmacology and physiologic chemistry. The work which is being accomplished now in these laboratories compares favorably with the work done in the countries with older scientific traditions and much more favorable surroundings. However, by this very departure clinical medicine itself suffered a visible retardation in the development of its own department. I discuss this phase not with pleasure, but the truth must be said. To my mind it is a fact that the leading clinicians of this generation do not compare favorably with their predecessors in this country, not to speak of a comparison with the leaders of clinical medicine in other countries. One of the reasons for the retardation in the progress is the loss to clinical medicine of the brainy men who now devote their energies to the pure sciences of medicine. Another reason may be found in the fact that by giving up pathologic anatomy and microscopy to special departments clinical medicine lost that part which has given it formerly its scientific character. An evident drawback to the progress of internal medicine in this country is the fact that its teaching at the present time is mostly still in the hands of men who received their medical training nearly exclusively in this country and at a time when pathologic anatomy was the exclusive basis and auscultation and percussion practically the exclusive methods of diagnosis. But in the last twenty-five years internal medicine changed its aspect greatly. The men who want to teach the medicine of to-day must have an education and training radically different from those which were customary and sufficient in former years.

However, the greatest evil of them all is the deplorable fact that in most instances internal medicine is taught in this country by very busy consultants who can give only a small fraction of their time and mental energy to this one of the side issues of their busy lives. Teaching medicine and furthering its science is a very serious business which ought to be carried on by men who are ready to devote all or most of their time to it.

Here are problems for you to solve. The progress of clinical medicine in this country has to be accelerated again. We might reach the level which we have seen to exist abroad. But we ought to strive to get still higher; in this field lack of modesty is a stimulating virtue. Look at the allied sciences of medicine, the level of which they have reached in a comparatively short time without any tradition and only through the activity of a small group of high-minded men. The progress of medicine in this country was always carried on by the few and not by the masses. 
Clinical medicine must reclaim some of the brainy young men who were enticed by the sciences of medicine. You represent a new generation. You have had an education and a training in modern medicine and the allied sciences. You have a training in investigation, the constitution requires it of you. The constitution which you have adopted shows your spirit. Among its objects is "the cultivation of clinical research by the methods of the natural sciences and the diffusion of a scientific spirit among its members." But you will accomplish more; the constitution imposes on you the obligation to be active in the diffusion of the principles of the society particularly among the students who come under your charge. I would recall this obligation to the minds of the members who were called within this year to chairs of medicine at influential places. The constitution does not keep you down exclusively to science, but let me tell you: beware of practice. It is a bewitching graveyard in which many a brain has been buried alive with no other compensation than a gilded tombstone.

One last word. The men whom you now see sitting on the bank left behind while the boat of progress swiftly glides away with fresh winds and under fresh sails were themselves in their youth passengers of similar boats and cut faces at others who were left behind. Be generous to them, but do not repeat their mistakes. The secret is : never leave the boat. 
II. FORMATIVE YEARS, 1909-1929

Dr. Meltzer's "New Science”. . . .

The early years of the Society were characterized primarily by the serious work of attacking the problems outlined by Dr. Meltzer and striving to realize the purposes set forth by the constitution. Society members went about these' tasks diligently and, for the first few years, with little to distract them.

The first annual meeting was held on May 10, 1909. Like the charter meeting, it took place at the New Willard Hotel in Washington. Subsequent meetings, prior to 1917 , were usually held at this hotel when the Society met in Washington and at the Marlborough-Blenheim when in Atlantic City.

Fifteen of the Society's 31 members were present for this first meeting. With Dr. Meltzer in the chair, a number of routine business matters were dispensed with-Treasurer Howland reported a balance of $\$ 109.70$ on the Society's books; officers for the forthcoming year were elected; a resolution on the death of one of the charter members, Dr. J. Dutton Steele, was passed; and new members were elected. It is interesting to note that this first meeting was the only one in the Society's history at which all nominees recommended by Council were not rubber-stamped into membership. Of a total of 20 nominees, eight were endorsed by Council, but of these, only seven received the requisite number of votes from the Society as a whole.

Following Dr. Meltzer's stirring address, the Society turned to the serious business of reporting the type of results which would further the causes he had outlined. The 12 titles on this program were as follows:

1. The blood pressure in tuberculosis-Haven Emerson

2. A modification of the Riva-Rocci method of determining blood pressure for use in the dogJaneway

3. The effect of compression of the splanchnic arteries upon the systemic blood pressure-Longcope

4. Blood pressure changes following reduction of the renal artery circulation-Janeway

5. Miliary tuberculosis of the skin-Tileston
6. The sensory symptomatology of the facial nerve-Hunt

7. A study of experimental anemia-Pratt

8. Observations on metabolism in cases of muscle spasms due to heat-Edsall

9. The relation of atrophy of the pancreas to glycosuria-Pratt

10. Some further observations on experimental nephritis-Christian

11. Some experiments upon the possibility of catheterizing the pylorus in dogs-Sailer and Torrey

12. Respiration by continuous intrapulmonary pressure without the aid of muscular actionMeltzer and Auer

Each of these presentations was discussed, no doubt in considerable detail and with frankness, by the members. Although the minutes do not record the particulars of what was said, the participants in the debate over each paper are noted and, after nearly all presentations, several men were ready with comments. In this respect, the first five meetings of the Society must have been particularly uninhibited, for it was not until 1914 that the first inevitable limitations on the scientific program became necessary.

At that meeting - the sixth-the chairman announced that due to the length of the program (29 papers were scheduled), presentations were to be held to 10 minutes, discussions to five. In addition, the Society approved a Council recommendation restricting the number of papers to be presented on succeeding programs to the first 30 received by the secretary, the remainder to be read by title only. This curtailment was not, however, imposed without comment. After hearing the Council suggestion. Dr. Meltzer rose to speak. He moved adoption of the proposed limitation, conceding that for the present it was necessary and, as a temporary measure, acceptable. But, he continued-and we can surmise from the secretary's notes the fervor with which he spokethe Society should consider changes of a much more radical nature for the future. There was no reason, he argued, why its meetings should be limited to a single day. He noted that membership had increased to more than 70 and that it was bound to increase still more. "Why," he implored, "should the Society continue to act like 
an appendix to the AAP? It can meet at any other time; it can meet for two days; and it can have more papers!"

Despite his urgings, the Society apparently did not even consider such possiblities until 1921, and then it was only to reject a suggestion for a two-day session. Nevertheless, the 1914 discussion underlined what was to be a continuously troublesome issue: the problem of accommodating more men and more papers while at the same time guarding high standards through the exercise of selectivity in membership and programs. Such problems did not, however, become really pressing until a somewhat later period.

Growth during these early years was fairly slow, but steady. Seven new members were elected in both 1909 and 1910, and five in 1911, bringing the total number to approximately 50 by the time of the fourth annual meeting. In the spring of 1911, a letter was sent to all Society members urging them to exercise more diligently their right to nominate worthy men for membership. As a result, nominations jumped considerably and 14 of 26 candidates were elected in 1912. By 1916, membership had increased to just over 100 and, again, limitations on the program became necessary. This time, the number of papers to be read was reduced from 30 to 25 , still to be presented in the order in which titles were submitted to the secretary. Neither this ruling, nor the earlier one, worked a great hardship in actual practice. Through 1920 the programs averaged about 27 papers and frequently. due to absences, fewer were actually presented at the meetings.

Perhaps indicative of the Society's complete preoccupation with the pursuit of knowledge during these years was the fact that all of its early presidents chose to bypass the "speech-making" prerogative of the office and, instead, devoted their opening remarks to a discussion of their own experimental work. Until 1917, with the exception of Dr. Meltzer's talk, the "presidential address" was simply the first paper on the scientific program.

Abstracts of papers read before the Society were published, for the first years, in the old Boston Medical and Surgical Journal (now New England Journal of Medicine) and in the Journal of the
American Medical Association, and reprints were usually distributed to members. In 1914, the question arose as to whether the Society should arrange to have its proceedings published privately at its own expense. Dr. Meltzer moved the adoption of this proposal, urging the chair to appoint a committee to investigate means of implementing it. He urged the publication not only of abstracts, but of discussions as well, arguing that higher dues to meet the added expense would be well spent for really good transactions.

Dr. Christian countered, expressing opposition to "expensive, extensive transactions," which, in his opinion, were "a sort of burial ground of papers." The private printing of brief abstracts and discussion summaries was acceptable, but if the proposal meant the regular publication of elaborate transactions, he viewed it with alarm. $\mathrm{He}$ was particularly concerned with keeping the dues low (they were $\$ 3.00$ a year at that time), contending that a higher assessment would be hard on men just beginning their careers. He concluded by remarking on the semantics of the issue: "If the transactions are to be put out in abstracted form," he said, "it might be well to call them something else, as they would scarcely be worthy of being dignified by the title of 'transactions.'”

To this outburst, Dr. Meltzer replied by saying that Dr. Christian's points were the very reason a committee was needed. Forthwith, his original motion carried and a committee consisting of the two protagonists and Dr. Roger S. Morris was appointed. The following year, the committee reported, in somewhat inverse form, as follows:

The Committee appointed by the President at the last annual meeting (1914) reports that it considers it as desirable that the American Society for the Advancement of Clinical Research shall henceforth publish a volume containing the transactions of each annual meeting, which would embody fuller information than hitherto, of the papers presented and the discussions which followed, a volume which should be accessible through libraries, etc., and which would lend significance and standing to the Association.

The Committee recommends further the appointment by the present president of a new Committee which, after listening to a discussion by the Society, should "consider the proper means for accomplishing this object."

(Signed) In favor of the above: S. J. Meltzer

Opposed: $\quad$ H. A. Christian

R. S. Morris 
There was no discussion on the matter from the floor and, with two members of the committee in opposition, the Chair ruled that the Society's proceedings would continue to be published as before. A complete list of sources of Society proceedings is included in Dr. J. Harold Austin's history of the Society (24).

In 1916, the name of the Society was shottened from "American Society for the Advancement of Clinical Investigation" to its present form. The minutes state simply that in 1915 President Cole asked for suggestions for a new name, the old being considered somewhat unwieldy. Two possibilities, each in the form of a constitutional amendment, were offered: "American Society of Internal Medicine" and "American Society for Clinical Investigation." The latter alternative was adopted, apparently with neither discussion nor dissent, the following year.

Perhaps the change was indicative of the fact that clinical investigation no longer required quite such active "advancement." In any case, the year 1916 marked the end of the Society's initial phase. Its life during the succeeding period did not differ radically, but it had become a going concern and changes were inevitable. As far as meeting places were concerned, 1916 marked the end of the New Willard-Marlborough Blenheim days, the advent of the "Traymore era." Although the Society remained a close-knit organization, 1916 marked the end, too, of a kind of intimacy manifested in part by the very personal nature of the records kept by its early secretaries. And finally, with America's impending involvement in the First World War, 1916 was, perhaps, the last year in which physicians were permitted the indulgence of single-minded devotion to the "advancement of clinical investigation."

\section{. . . And How It Grew}

In 1917, the Society turned its collective attention for the first time to problems of a medicopolitical nature by adopting two resolutions pertaining to the war. The first, introduced by $\mathrm{Dr}$. Leonard G. Rowntree, was in response to the $\mathrm{Na}$ tional Research Council's call to arms. It read as follows :

Whereas, the National Research Council invites the cooperation of educational institutions in the promotion of research at this critical period in our national progress$\mathrm{Be}$ it Resolved that we, the American Society for Clinical Investigation, hereby offer, through the President of the Society, our services and heartiest cooperation to the National Research Council on the lines of investigation which it considers most needed at the present time.

This was followed up two years later when Dr. Christian, then president of the Society, reported on a meeting of the National Research Council's Division of Medical Sciences of which he was Resident Chairman. In 1922, Dr. Means was appointed as the Society's representative to the National Research Council and thenceforth unto the present day the Society has maintained a somewhat "off-again, on-again" relationship with the Council.

The second resolution, probably the Society's one and only contribution to the cause of prohibition, is rather amusing in the light of a later day. At the time, it was in the direct line of patriotic duty. Introduced by Dr. Edsall, it read as follows :

Resolved, that in the critical condition of the world's food supply, we consider it desirable that the manufacture of alcoholic beverages or their importation into this country be prohibited for the duration of the war and for at least one year thereafter.

It was passed, though apparently soon forgotten. As one member put it, "No one talked about prohibition when I got in in '22!" Be that as it may, everyone talked about prohibition in 1917. On the national scene, the anti-alcohol crusade had begun back before the turn of the century and by the time war was declared, two-thirds of the states had succumbed to its advance (25). The ease with which liquor could pass into these dry states from the wet areas led to a rising demand for national prohibition and in 1913 Congress passed the Webb-Kenyon act, penalizing shipment of alcoholic beverages into states where their sale was prohibited. When the United States entered the war, a nationwide ban on the sale and mant1facture of all intoxicants was enacted ostensibly, at least, on grounds of national economy and efficiency. Whether "the critical condition of the world's food supply" actually had anything to do with the Society's action is open to speculation. But it was as likely a reason as any.

In addition to these two instances of response to national duty, another outward-looking feature 
appeared on Society programs. This was the new style presidential address. In 1917, Dr. Haven Emerson departed from the pattern set by his predecessors and delivered a talk entitled "The Community as a Patient Needing Clinical Investigation." The following year, Dr. George Blumer addressed the meeting on "Medical Education in Relation to the War." From that time forward, with occasional exceptions, Society presidents have put themselves in a "watchdog" role, commenting on current conditions in clinical medicine in general and within the Society in particular, warning of potential pitfalls, and pointing to areas wherein changes are needed. The end of the First World War and the Society's tenth anniversary provided the point of departure for Dr. Christian's address entitled "The Work of the Medical Clinics" given at the 1919 meeting. ${ }^{\circ}$

The Society's first decade, Dr. Christian felt, could be regarded with satisfaction. "Gentlemen," he said, "much of what Dr. Meltzer outlined has been accomplished and this Society and its members have had a large share in bringing about the change." He continued, however, with a warning against complacency :

To readjust ourselves to pre-war conditions is not easy ; even to do this should not satisfy us; improvement in medical conditions alone should satisfy us. . . . This Society exists primarily for the encouragement of investigation. We must take counsel as to how this can be accomplished in the best possible way. ... As chiefs of clinics what should be our attitude toward our junior men? Why have we not in the past developed better men in our clinics?

In presenting his own answers to these questions, Dr. Christian cited selfishness on the part of the department head as the primary cause of failure. Although it was important that the chief be responsible for work issuing from his service or laboratory, Dr. Christian looked with extreme disfavor on the department head who consistently took more than his share of the credit for such work. He stressed the importance of giving assistants freedom in their investigations, of encouraging the development of independent thought. On this score, he said:

- A copy of this address, which was never published, was obtained through the courtesy of Dr. C. Sidney Burwell.
Personally, I have never cared for the method of outlining an investigation for an assistant, and when that is finished, outlining another. In the long run I think it is better to let the man drift in his work for awhile until he can see a problem for himself. . . . This is rather a kill or cure method, but after all is it worthwhile for the man without imagination and curiosity to investigate? I believe not; he has a place and a work to do but it is not in pestigation. To lead him to think he will succeed in investigation is doing him a wrong.

Ten years earlier, Dr. Meltzer had spoken of the need for clinical investigation to reclaim some of the "brainy young men" who had been lured away from medicine into the laboratories of the allied sciences. In this light, the following passage from Dr. Christian's address is rather interesting:

Our recent development in the clinics (has) worked to weaken the fundamental sciences by taking from them a valuable group of workers, namely, those planning a career in clinical medicine. I believe it would be wise to return some of these for a year or so of work in these laboratories during the course of their training for internal medicine. To do so would be helpful both to the fundamental sciences and to clinical medicine.

The growth in the number of workers engaged in clinical research had, indeed, been rapid during the Society's first decade of existence and it was to become even more rapid during its second.

The years between 1910 and about 1935 witnessed striking advances in the status of investigative medicine and a veritable revolution in American medical education. The birth of the Society was nearly simultaneous with that of another institution destined to be of far-reaching significance for the future of American medical research-the Hospital of the Rockefeller Institute. Opened in October, 1910, the Rockefeller Hospital was the first in the country to be built especially for, and devoted entirely to, clinical investigation. In the years following its establishment, it exerted a profound influence on the modernization of academic medicine, serving as a model for the clinics then being established or reorganized on a full-time basis in universities both here and abroad and as a training ground for the men who were to staff them. Indeed, this was one of the avowed aims of its first director, Dr. Cole (14) :

As soon as the work was under way I realized that owing to conditions then existing in medical teaching the hospital should have at least one other function beside the investigation of disease. The idea of so-called university departments of medicine was in the air and it 
was evident that this idea would soon reach concrete expression in a number of places. The new hospital appeared to be the logical place in which leaders of this new movement could be trained and be given opportunities to work and be fired with the spirit of investigation which could thus be disseminated throughout the projected clinics. It seemed that the hospital should not adopt a policy of "splendid isolation" but should play its part in the reorganization of medical teaching in this couptry.

That it succeeded admirably in this role is evidenced in part by the fact that in 1938, of the 179 persons who had been on the Hospital staff during its 28 year existence, $112-62.5$ per centoccupied full-time academic positions and many more had university affiliations of one kind or another (14).

The full-time system in clinical teaching was initiated in the United States with its establishment at Johns Hopkins in $1914(9,10)$ after Acting President William Henry Welch had obtained from the Rockefeller Foundation's General Education Board a grant sufficient to endow fulltime chairs in the departments of medicine, surgery and pediatrics. It was instituted, however, only after a considerable battle between supporting and opposing factions of the medical faculty to win over the Hopkins Board of Trustees. Dr. Barker was among the foremost advocates of the full-time plan. When he had been called to succeed Osler as professor of medicine in 1905, he had petitioned the Board of Trustees to allow him to accept the position on a full-time basis but his request had been denied and, like his counterparts of that day, he had been forced to divide his time between university responsibilities and a private practice. In 1914, after the climate had changed, he was offered Hopkin's first full-time clinical position but by that time his practice had become so extensive and so closely integrated with those of other Baltimore physicians that it would have been difficult to abandon (10). It was left to his successor, Dr. Theodore C. Janeway, to become the nation's first full-time professor of medicine. To do so, he gave up a lucrative practice in New York. Dr. John Howland, like Dr. Janeway a charter member of the Society, was Hopkins' first full-time professor of pediatrics.

During the ensuing years, although the fulltime system caught on and began to spread to other institutions, it encountered rough going.
Perhaps the major point of contention was whether or not full-time teachers should continue to see private patients. The argument in favor of their doing so was based partly on the desire to supplement academic salaries, partly on the view that the teacher of medicine should retain contact with the care and treatment of patients beyond that connected with his duties in the university clinic. The full-time system as established at Hopkins (and at such other institutions as Washington, Rochester and Yale Universities where Rockefeller Foundation grants supported clinical chairs) carried with it the understanding that fulltime staff members would not accept fees from the treatment of patients which they might undertake on their own $(10,21)$. Such fees, rather, were to be used by the departments, a stipulation designed to assure that the attention of the nowsalaried clinicians would be focused exclusively on their university responsibilities-teaching, care of patients in the clinics, and research.

When Drs. Edsall and Christian established full-time clinical teaching on a firm basis at Harvard University, they developed certain variations on the Hopkins plan. Of the issues involved and of the "Harvard full-time system," Dr. Means (13) has written the following account:

... A policy question arose about just how much private practice the so-called full-timers should be atlowed to do. Edsall consulted the trustees of the hospital about his own case, and all he could ever get out of them was that they considered him a gentleman and they hoped that he thought they were! The policy finally arrived at was that the amount of private practice should not be more than was consistent with doing a fair measure of full-time work. It was more a moral than a legal issue. Through the years it has undergone some modifications. How the private practice of the full-timers was to be paid for was also a problem. At Johns Hopkins Hospital-where, with abundant aid from the Rockefeller Foundation, the major clinical departments had been put on a strictly full-time salaried basis (staff members) were expected to live on their salaries. They could take care of patients privately, but the fees collected for such service went to the hospital and were applied to departmental budgets.

Edsall considered such a policy unsound. Inherent in it was the danger that the full-time staff could be exploited by the institution and forced to make a substantial contribution to the departmental budget by caring for private patients. It was possible, although not inevitable, that such a system could lead to serious encroachment on the academic services of the full-time people. He ar- 
ranged, therefore, that the full-timers collect their own fees for the small amount of private practice (they) performed. This policy became known as the "Harvard full-time system."

During the 1920's, the adoption of the full-time system was greatly accelerated, and of the situation as of about 1932, Dr. Robinson (10) has written :

Medical education in this country seemed to have become mature. The great medical development of Columbia University and the Presbyterian Hospital in New York, opened in 1928, was the outstanding medical center of the new type; the New York Hospital-Cornell Medical Center began its operations in 1932 . In the meantime, new schools had been created at the University of Rochester and at Duke University. The medical schools of Vanderbilt and of the University of Chicago had been reorganized along the new university lines, and the development of clinical departments with full-time teachers was well under way.

Such developments did not come, however, without creating new problems in the realm of academic medicine. One of these was the subject of an address entitled "What Should We Do With a Harvey or a Laennec?" given in 1927 by Society President Eugene F. DuBois (26).

"With the tremendous growth of our medical clinics and medical schools," Dr. DuBois said, "we are in danger of being swamped in this process of expansion." $\mathrm{He}$ traced the hypothetical course of the clinical careers that a young William Harvey or a young René Theophile Laennec might follow in current America, lamenting the probability that, after an initial period in which they would be allowed to devote full time to research, their remarkable talents would be dissipated by increasing administrative, teaching, and consulting responsibilities. "What would become of the discoveries that made Harvey the founder of modern physiology or the pathological studies that made Laennec the founder of modern clinical medicine? How much time would be left for quiet work and contemplation?" Dr. DuBois asked. He continued:

The situation would not be serious if it only meant the loss of the original investigations of a few such men. There is a more serious loss; that is the gradual atrophy of the research spirit through disuse. The true research spirit can be maintained only by means of personal contact and participation in the experiments. The head of the clinic is seldcm allowed enough time for that study and work which alone will keep him the best informed man in his own particular field. The university scatters his energies over a broad expanse, part of which is as sterile as the Desert of Sahara.

Dr. DuBois attributed these failures to "the desire for bigness on the part of our universitites," and concluded, with respect to Harvey and Laennec, that "after a good look at the present conditions they would realize that they would be happier in their own small, inefficient, but comfortable, centuries."

The infiltration of a "mass-production mentality" into the realm of science was enlarged upon by Dr. Robert F. Loeb (27) in 1936. In considering the merits of the two general approaches to research-individual effort vs. the more recent "research project"-Dr. Loeb cited the experience of the past in upholding the view that it was the work of the creative individual, motivated by intellectual curiosity and capable of critical thought and imaginative experimentation, which offered the greatest hope for progress. Of the research project, he said, on the other hand:

(It) demonstrates in its point of view total ignorance of the means by which science has advanced. It attempts to force progress through regimentation. ... It stifles the untrammeled play of imagination. ... It is not the product of creative thought, but is usually initiated by energetic and misguided promoters inspired by the effectiveness of mass production in big business. . . . In other words, it assumes that scientific knowledge can te bought, and that dollars give birth to ideas. The research project in clinical medicine has proven consistently barren and has resulted in the disbursement of funds which, if applied to the endowment of individual investigators or university departments where creative thought is fostered, may reasonably be expected to further the progress of science.

The expansion of clinical teaching and research which gave rise to such outcries made its presence felt in the Society's swelling membership ranks and plethora of papers as well. During the years following World War I, the problem of increasing numbers demanded almost annual attention. For the first time, the principle of selectivity was introduced in making up the program. Previous limitations, it will be remembered, involved setting an arbitrary quota on the number of papers to be read and filling it on a first-come, first-served basis. In 1920, Council recommended that preference on future programs be given to members who had not presented a paper the previous year. 
This, however, did not make any assumptions about the comparative merits of the papers thus presented. In 1922, under increasing pressure to accommodate more titles, the Council took cognizance of the fact that the earlier method of making up the program did not necessarily result in the best selection. The Society voted that in the future selection would be left to the discretion of the president and, to assist him in his choice, abstracts were to be required. In 1924, restrictions having to do with qualifications to be met before a paper would be considered were introduced. The rulings passed that year provided that 1) no paper was to appear on the program unless one of the authors was a Society member; 2) except in the case of joint authorship, each member was limited to one paper; and 3) prior publication barred a paper from the program. These rulings were amended in 1931 to allow nonmembers to read papers if they were introduced by a member and associated with his clinic, and if the member himself did not have a paper elsewhere on the program.

In 1921, the minutes of the Council meeting contain the first mention of what many Society members consider "the most important thing in the Constitution"-the provision for emeritus membership. Council discussed the matter at that time, but the record gives no information beyond the decision that it was a subject which could most properly be presented in the form of a constitutional amendment if any member so desired. Such an amendment was introduced two years later and passed in 1924. It read as follows:

The number of active members shall be limited to two hundred. Active members, whose membership has extended throughout 20 years, will automatically be transferred to emeritus membership, and those whose membership has extended throughout 10 years or more may at their own request be transferred by the Council to emeritus membership. Emeritus members shall be entitled to attend all meetings, but not to vote or hold office. They shall be exempt from dues.

This was modified in 1929. That year, Council heard a letter from Dr. Reginald Fitz urging that membership in the Society be increased to allow men to be elected earlier in their careers. After lengthy discussion, it was the consensus of the Council "that the Society should be kept in the hands of younger men." To effect such a policy, rather than lift the ceiling on membership, it was decided to make transfer to emeritus standing automatic at the age of 45 . Dr. Walter W. Palmer was delegated to present an amendment to that effect at the business meeting and it was approved the following year. With its adoption, 55 members moved into the emeritus class.

Still another indication that the Society was rapidly splitting its original seams was the discussion, on several occasions, of the possibility of establishing subsidiary societies in order to accommodate the younger men. This matter first came up in 1921 when President Leonard G. Rowntree (28) called attention to the Society's obligation for "the diffusion of a scientific spirit." A.fter dealing at length with the elements of this spirit-its acquisition, cultivation and dissemination-he opined that the Society could, and should, do considerably more to further it. To this end, he advocated the formation of local societies on which the Young Turks might draw for their membership and appointed a committee consisting of Drs. Miller, Peabody and Hewlett to explore the possibility. The committee's report, made the following year, follows :

After investigation and consideration of the subject your committee believes it inadvisable at the present time to establish branch societies. In all of the larger cities there are medical organizations in which the young man in internal medicine may become a member and thus obtain the stimulation which arises from contact with others.

It is recommended, however, that every member of the Society try to keep in touch with younger men of special promise in his community and encourage them to qualify for membership in this Association. By pursuing this course all eligible physicians may be given the opportunity to become members.

The idea, however, did not die. Despite the committee's optimism, there was a clear need to make provision for the rapidly rising numbers of young men eager to participate. Dr. Meltzer was among those who expressed concern over this matter, as evidenced in the following account by Dr. Pratt (8) :

I saw him (Meltzer) in New Haven a few months before his death (in 1921). He was in bed recovering from a severe attack of cardiac asthma during the preceding night. I had arranged a consultation with Wilder Tileston. When we entered the room, Dr. Meltzer refused at first to discuss his own symptoms but at once began to talk about the Society for Clinical Investiga- 
tion. He said "I think the Young Turks are getting rather old. I believe there is a great need for a second society composed of younger men." Even at the time he spoke, which must have been ten years ago, conditions were similar to those that existed when he formed our society.

The need for a junior organization is still greater now (1934). Young men have to wait as long before they gain membership in the ASCI as we were compelled to thirty years ago before getting the privilege of presenting our work before the AAP.

The idea of junior societies was particularly dear to Dr. Rowntree and in 1927 he and his colleagues at the Mayo Clinic proposed the formation of the Central Society for Clinical Research. In a letter to the Council, Dr. Rowntree asked the blessings of the Young Turks for the new organization. After lengthy discussion, the Council drew up the following recommendation for presentation at the business meeting :

In view of the benefits to be derived by younger men in a society for clinical investigation, this Society is glad to learn that the organization of a society with a similar purpose is contemplated in the Central West. The Council heartily endorses this move and recommends that this Society extend its best wishes for the immediate success of the new society.

This recommendation was approved by the membership initially, but as the business meeting drew to a close, Dr. Alfred E. Cohn moved to re-open discussion and suggested that the chair appoint a committee to consider relations of the Young Turks to other societies for clinical investigation in the United States. His motion carried and a committee consisting of Drs. Homer F. Swift, Rowntree and Longcope was formed. Although the minutes note that it was dissolved two years later, no account of its findings is given. Presumably, although the Young Turks did not feel it desirable to affiliate in any formal manner with the new society, its formation, like that of the American Federation for Clinical Research in 1941, was regarded as a happy, if only a partial, solution to the membership problem. Proceedings of the Central Society's annual meetings were published in the Journal of Clinical Investigation for a good many years.

Despite such indications of growth, the Society up until the Second World War retained many of the attributes of an intimate, informal organization. Emeritus members reminisce about the "good old days" when meetings were small-say 100 or 150 in attendance-and the "boys took down their hair and tore into each other." Not the least of the benefits derived from such meetings were the friendships they fostered. In this respect, the "extracurricular activities" of the Young Turks were frequently as important as the scientific sessions, and a number of traditions evolved. It was customary, after adjournment, for members to reassemble in small groups in the hotel rooms to rehash the program-with or without the usual beverages of prohibition days. Later, many of the post-meeting discussions were held at the Brighton Hotel where members "let down the bars" over the famous Brighton punch, a rum drink remembered almost universally by men who were active in the Society during the late ' 30 's and '40's. Since then, the Brighton has been demolished and, although its successor-the Colony Resort Motel-still has proprietary rights over the "Brighton" punch, the luster associated with it in the old days is gone.

From the Brighton, the Young Turks often proceeded to Hackney's for lobster and thence, not infrequently, back to the Brighton. In any case, it was, traditionally, "a pretty rough night." The aftereffects were equally traditional. According to one member, "No one ever came back without some kind of intestinal upset," a situation which their wives blamed on drink but which the Young Turks themselves were inclined to attribute to lobster. There was some truth in the latter interpretation for, as another member put it, "There is little doubt that Atlantic City sea food had been a long time away from the sea-it usually came from New York."

Whatever the truth may be, it should be emphasized that these annual "Monday nights" were profitable as well as enjoyable. They resulted in the formation of many close and lasting friendships and saw, no doubt, the excited conception of many ideas which were to come to life in the form of substantial contributions to the progress of medical science. 


\section{CONFLICT AND COMPROMISE,} 1930-1945

\section{Scientific Soul-Searching}

The burgeoning of interest and activity in clinical research which had accompanied the Society's first 20 years of existence was not regarded by all investigators as an entirely unmixed blessing. By 1930, there was a fair danger that the wave of popularity on which investigative medicine seemed to be riding would turn into a veritable deluge, swamping the "boat of progress" to which Dr. Meltzer had alluded some two decades earlier and wresting it from its course. There seems, in fact, to have been some confusion as to what the true course was, a matter which received considerable attention during the Society's third decade. Dr. Loeb, president in 1936, made some particularly pungent observations on the situation (27) :

Keeping pace with the spirit of abandon which characterized the florid twenties, clinical investigation ran riot, recognizing no bounds, philosophical, intellectual, technical or financial. . . . Under this spell of enthusiasm it seemed reasonable to expect that with organized groups of investigators, spacious laboratories, endless equipment and technical assistance the mysteries of medical science must bow before the concerted onslaught and bow promptly. Medical students and young graduates, without consideration of "Geist" or other qualifications, were urged to enter laboratories. They might cooperate in the contemplated discovery of the etiology of cancer or they might be set the task of counting paving blocks-it was immaterial, but all in the name of science.

From many quarters, voices were being raised in concern over what Dr. Loeb termed "this great orgy of clinical investigation." Prevailing attitudes, underlying concepts, methodological convictions-all were called into question. Were the universities turning out anything more than rank after rank of highly skilled technicians? Was there any coherence amidst the feverish flurry to produce and publish; or were physicians, in their zeal to be men of science, concerned only with the fragmentary analysis of the phenomena of disease, failing in their haste to ask significant questions and ponder the meaning of their answers? Were some being motivated merely to do the "fashionable" thing? Why the deification of measurement, the aura of sanctity surrounding experimentation? Had clinical investigation been too narrowly de- fined? Was it losing sight of its "clinical" aspect? Wherein lay its future?

These were among the questions being debated throughout the late 1920's and '30's. Certainly some of them had been asked and answered earlier, and certainly most of them continued to be re-asked and re-answered later. But, roughly speaking, such questions seem to have come into particular prominence during the Society's third decade.

The writings of Dr. Alfred E. Cohn are illustrative of the type of re-examination of medicine's philosophical bases which was prevalent in some academic medical circles of that day. Many of his essays dealt with the question of whether clinical medicine could legitimately be considered a science, a question which was still much debated during the 1930's and which, particularly in British medical circles, was quite often answered in the negative. Cohn was an ardent apologist for the view that medicine was, indeed, a science and one of his earliest (1924) essays, "Purposes in Medical Research: An Introduction to the Journal of Clinical Investigation," was devoted to a discussion of this belief (29). The following excerpts from this article may serve to indicate his general approach.

After enumerating historical instances in which medicine, to its detriment, had been sidetracked by attempting to borrow the methods of other disciplines (the iatro-mathematical school of Borelli, for example) for application to the problems of human disease, Dr. Cohn said:

The employment of a method presupposes that ... the method selected is advantageous in the solution of the problem. .... Mathematics, mechanics, physics, chemistry, physiology as independent disciplines has each had its proper objects of inquiry; all have been aware of their appropriate problems in the phenomenal world. . . . But the primary objects of interest in medicine cannot properly be stated in terms appropriate to them. ... Medicine must, like the other sciences, be properly credited with having specific objects of interest on its own account. If it is true that medicine has not always been clear as to what these objects are, this may be due to the fact that the definition of its objects has not always been clear. It may perhaps be for this reason that it has so often been deflected from the straight path of its proper pursuit.

In proceeding to his own definitions of the 
"legitimate scope and objects" of medicine, Dr. Cohn said :

The phenomena of interest in medicine are the phenomena of disease as these are manifest in affected persons. They are phenomena which exist as concrete entities in nature, they are indivisible, and they fall within the province of no other inquiry. They constitute the proper concern of medicine. ... When we come to the question of how to investigate them we find that they are to be studied by no single methodology any more than are those of the (other) ... sciences. The methods to be employed are those which are appropriate to illuminating the specific problems in question.

The increasing tendency among investigators to adulate experimentation at the expense of the descriptive method received the frequent attention of critics during these years. It reflected a significant change then occurring in medical research: the growing reliance of clinical investigators on experimental and quantitative methods (11). The shift produced a rift of some proportions among clinicians. The experimentalists regarded representatives of the descriptive school as being somewhat old fashioned, while the latter decried tendencies to limit the definition of research to experimentation alone and, in the words of Shryock (11), to accept "any experimentation whatever as ipso facto worthwhile." This split affected the Society as well. By the late 1930's, most of the members of the Council were experimenters and, according to Dr. Isaac Starr (30), "looked upon the descriptive school as being dated." This fact inevitably influenced the Council's selection of candidates for membership and, as would be expected, brought numerous repercussions.

In 1931, Dr. Francis G. Blake touched on this issue during the course of his presidential address (31). Discussing the meaning of the phrase from the Society's constitution-"by the methods of the natural sciences"-he said:

At the risk of stressing the obvious, let me make it clear at once that I conceive this phrase to refer, not to the techniques or tools used, but to the methods of approach employed in the natural sciences. There are, of course two methods-on the one hand, observation, analysis, and deduction, the so-called descriptive method, still held honorable by some because of its antiquity if for no other reason; on the other hand, the inductive, experimental method, held, it would appear, in higher esteem by most because of its relative youth and vigor.
He continued by calling argument concerning the relative superiority of either method a "somewhat fruitless pastime" and terming "narrow and partial" the view that the experimental approach was necessarily preferable. Both, he said, have their proper place. The important thing was that the investigator stop to think about what it was he hoped to accomplish, regardless of which method he chose.

The importance of clinical observation was further emphasized by Dr. John R. Paul in 1938 in an address entitled "Clinical Epidemiology" (32). He outlined what he called a "new science" in which he proposed that Society members take part by making observations on what happened to patients outside of the hospital as well as inside. Thus it was a science concerned with the circumstances, whether functional or organic, conducive to disease. But to qualify for the name "clinical," Dr. Paul said, such a science would have to concern itself with the interpretation of these circumstances, branching out from a study of the sick individual to a study of his situation, bringing critical judgment to bear on the context out of which disease had arisen. Such a concept, Dr. Paul noted, was old hat to the family doctor. But, he said, "Now that emphasis, for this Society at least, has shifted away from the home and into the Hospital and Dispensary, clinical epidemiology will be practiced only if we take thought of it."

The real value of such studies, Dr. Paul emphasized, lay not simply in the discovery of new intrinsic or extrinsic factors, but in the discovery of new concepts. He continued:

This is all so obvious that it hardly seems worth mentioning, and yet a dominant thing about some of our present notions of causative factors is that unless they fit into a modern pattern of our own liking they are apt to be overlooked. Of late years, conservative opinion does not allow anything to be really considered as "etiology" unless we can succeed in getting it into a test tube, unless we can precipitate it-unless we can crystallize it, as it were. This is due of course to our current methodology which has, perhaps, become more of a religion than most of us realize. I think it may have led to a slightly narrow interpretation of clinical investigation on our part, for clinical investigation must be given the opportunity to spread itself up into philosophy if it will, as well as down into the basic sciences. 
Although there was no serious argument with the need for a philosophical and synthetic approach to experimental medicine, the main current of development in clinical investigation continued to be analytical as new chemical and physical methods were introduced into the study of disease processes. Despite the paternal admonitions of many of the older members, the Young Turks continued to seek the "precipitates" and "crystalline substances" associated with disease. In this search they were aided by a multitude of new instruments rapidly becoming available for application to clinical problems, instruments which frequently opened up whole new areas for research (11). Medical technology grew increasingly complex. At one point, it was seriously suggested that medical schools should establish separate "departments of instrumentology" for the common use of all staff members, a development which might have avoided what Dr. Carl V. Moore called in 1954 "scintillation counter-Beckman disease" in which every department and laboratory engaged in the conspicuous consumption of apparatus to the detriment of the budget and without regard for duplication (33).

Some of the older members viewed with alarm what seemed to them a bewildering succession of "fads and fashions" in medical research. The younger men, they felt, in their anxiety to succeed in the "right" field often made idols of each new methodological innovation that came along, worshipping now "at the shrine of the colorimeter," then "at the shrine of the electrocardiogram" and later still, "at the shrine of the potassium ion." While some such cautioning was undoubtedly well-taken, the majority of the young men on the firing line felt that they were able to adopt new methods and acquire new technical skills without losing perspective on the ends which were thereby being served. The science of clinical investigation was, in the long run, greatly enriched by the growing array of instruments and techniques which enabled clinicians to transcend simple observation in their study of the mechanisms of disease.

\section{Space, Time, and Learned Societies}

Moving out of the '30's the focus of presidential concerns seemed to have undergone a slight shift.
Greater emphasis was placed on what might be called functional aspects of the organizationspecific policies or general considerations of purpose-and less on scientific points of view. True, the two are in some sense opposite sides of the same coin. The scientific substance which comprises the Society's "raison d'etre" is, at bottom, the factor which determines its policies and which must be kept in mind in guiding its practical affairs. But, whereas presidents during the '30's seemed to concentrate on the scientific side of the coin, those of a little later period tended to reverse it. Thus, Dr. Tinsley R. Harrison (34) dealt, in 1939, with what he called "institutional arteriosclerosis." (This address, incidentally, was never delivered before the Society. Dr. Harrison had prepared it for the meeting and submitted it to the Journal, but in a last minute burst of enthusiasm about some research which had just been done in his laboratory, he decided to tell the Young Turks about that instead. The originallyscheduled address was, however, printed in the Journal.) Noting that medical societies and medical schools, like other cultural organizations, were subject to decay, Dr. Harrison suggested that the root of the trouble, so far as intrinsic causes were concerned, was failure to select the best possible men.

In drawing attention to the importance of choosing good men, Dr. Harrison touched upon one manifestation of a more fundamental problem, one which had become increasingly troublesome as the boom in research activity brought pressure on the Society to expand its membership and scientific programs. It was a problem which Dr. Isaac Starr treated more extensively when he succeeded Dr. Harrison to the lectern in 1940: that of the conflict, common to many learned societies, arising out of the dual aims of setting a standard and performing a service (35).

Dr. Starr, according to the minutes of the 1940 meeting, "addressed the Society on the subject of functions and dysfunctions of learned societies, providing ingenious models representing important concepts of space and time in their relation to the duties of said societies." This was in reference to what must have been one of the lighter moments on that year's program, a demonstration staged by Dr. Starr with the assistance of what 
was described as "a curious looking object which at a distance resembled an orange thrust through with a multitude of long steel knitting needles that radiated from it in all directions . . . placed beside a clock." It was, the president solemnly explained, "a representation of our Society radiating its beneficent influence in almost every direction. ... This timepiece," he continued, "is an integral part of the model, for it indicates that the influence of our society extends, and will extend, throughout time." It was also, as Dr. Starr went on to announce triumphantly, a demonstration of interorganizational one-upmanship, for the addition of the clock made his model four dimensional and therefore one dimension up on that produced by his friend, Dr. DuBois, for the benefit of the AAP audience the preceding year (36).

Dr. Starr's visual aids, however, supplemented an otherwise serious talk in which he discussed the two functions of the Society-those of performing a service and of setting a standard. Among its services he enumerated first, the publication of the Journal which he termed a "godsend" to "those of us who are considered to be clinicians by physiologists, biochemists, and immunologists; and considered to be physiologists, biochemists, or immunologists by most clinicians." By serving as an organ for clinical research made by quantitative methods, the Journal, he said, was "in the forefront of that change from descriptive and qualitative methods to the more exact quantitative measurements ... which has made possible the great advances of physics and chemistry and may well produce as great a revolution in medical practice."

Second among the Society's services he listed the annual meetings. Here, Dr. Starr was a little more critical. "Our programs have contained very little of what might be called synthetic thinking," he said. Insistence on demonstrated fact had been important in rescuing medicine from the "fanciful speculation" that had characterized it 100 years earlier, but, Dr. Starr stressed, all facts are not equally important:

In every investigation there is a period when one must decide which facts are worth discovering. To do this logically, one must picture to himself what the situation is. ... In my opinion, our program would be improved by studying the methods of the great English school of physiologists whose members have never been afraid to attempt to synthesize the facts into simplifying theories. ... We are spending much time, effort, and money in our clinics accumulating records, apparently in the pious hope that some day somebody is going to synthesize something useful from the multitude of data they contain.

The Society's third means of performing a service was considerably less tangible, Dr. Starr said, but no less important. It consisted of fostering acquaintance among investigators. Often, he felt, personal questioning revealed far more about a subject than did reading of the literature, and he expressed the hope that contacts afforded by Society meetings would be of the sort to facilitate cooperation rather than to create rivalry.

By and large, Dr. Starr thought, there was little doubt about the quality of the services rendered by the Society. The real problems began when it attempted to exercise standards through such functions as the selection of members and of papers for the scientific program and the Journal. In all cases, the pool from which selections had to be made was large in comparison with the number which could be chosen; the task of selecting was complicated and mistakes inevitable. This underscored his final point-that the dual functions he had outlined were to some extent conflicting :

There are some who think that the membership should be enlarged and the program expanded. Their aim is to improve the service given by the Society. This is opposed by others who point out that such a change would lower our standard of excellence.

Too much emphasis on standards is a cause of decay; often it is a psychological defense mechanism set up by persons no longer productive. The organizations which become more and more exclusive tend to die of dry rot. Mistakes made in the enforcement of the standard make them ludicrous. . . . Nevertheless, while undue insistence on standards causes difficulties, abandoning them too far in the interest of service brings troubles of another sort in its train. For then the door is opened for the man whose real aim is personal advertisement rather than the search for truth. Uncensored programs are likely to be too long. Societies with low entrance requirements become so large that friendship between the members becomes impossible and the personal service on which I lay so much value is non-existent.

Thus, Dr. Starr continued, a compromise between services and standards was necessary and in attacking this problem, as well as others, he felt that two principles should be kept in mind. Dramatically, then, he produced his model. In all its 
four-dimensional glory it was intended, he said, to illustrate his first point :

In dealing with learned societies, let us preserve our sense of humor. In some of the letters received by the secretary a sense of humor has seemed strangely lacking. The errors of today, if they be errors, can and must be corrected tomorrow.

He concluded by urging as a second general principle the greater use of ordinary processes of democracy. All too common among medical societies, he said, was the tendency of members to let officers handle all the affairs and to be negligent in attendance at business meetings. Against this tendency he cautioned the Young Turks to be on their guard.

Dr. Starr's message is an important key to an understanding of the basic issues at stake in the debates and decisions which constitute the Society's policy-making history. From the outset, the Young Turks had stood for quality in clinical investigation but, while it was never suggested that the traditionally high standards should be sacrificed, the problems of maintaining them in the face of recurrent pleas for enlarging the membership and expanding the program-pleas, essentially, for an extension of services-grew more and more difficult. As Dr. Starr pointed out more recently $(30)$ :

While I was a member of the Council (1939-40) the problem of policy being vigorously debated was one much to the front throughout all American learned societies. Of the societies senior to ours, the Association of American Physicians had taken one course; that is, it had continued a policy of limited membership and still has maintained that tradition, and (has) continued the tradition, of one program. On the other hand, the societies of the Federation, like the Physiological Society, followed the course of admitting everybody who seened to be qualified, allowing every member to present a paper, and simply expanding the program until there was a multiplicity of simultaneous sessions.

For the Society, the decision was not quite so clear-cut. Debate over membership policy and type of program had been a continuing phenomenon since Dr. Meltzer's fervent plea at the 1914 meeting, but during the 1930's, the problems of accommodating more men and more papers became particularly acute.

The Young Turks had entered the '30's with their collective heads bumping against the 200member ceiling which had been imposed in 1924 the 1929 catalogue lists 201 active, and 34 emeritus, members. When, in the following year, transfer to emeritus standing became automatic at age 45 , some head room was provided, but the repreive was only temporary. The number of candidates tended upward while the number of available places fluctuated but little and, by 1938, membership in the active category had climbed back to 199 and emeritus members numbered 174 . Thus, within 10 years the Society had once again reached its upper limit and as it emerged into the succeeding decade it had, literally, to raise the roof. Constitutional amendments introduced in 1941 abolished the limit of 200 and established, instead, a quota on the number to be admitted annually-either 25 or the number corresponding to the number of transfers to emeritus status, whichever was larger. Although these changes effected a slightly more flexible membership policy, they did not forbode a significant increase in the Society's size, and it was in this year that Dr. Christian led a number of the disgruntled candidates off in search of a new society, the American Federation for Clinical Research.

Not only the size, but the composition of the membership was called into question. We have already noted that the experimentalists were at odds with representatives of the older descriptive school. There was, in addition, some debate arising out of the increasing degree of specialization in clinical research and its effect on the selection of members and programs. According to Dr. William S. Dock (37), an active member throughout the 1930's and early 1940's, "The row over making is all good internists, equally interested in physiology, biochemistry, microbiology, endocrinology and hematology or specialists listening only to other specialists began during this period." In later years as well, members have alternately petitioned Council to restrict membership to internists or to counterbalance their preponderance by admitting larger numbers representing other clinical specialties or the basic sciences. Pressure has been exerted, too, for sectional meetings for the presentation of papers dealing with subdivisions of clinical research, but not until very recently has this suggestion been effected through the joint Society-Federation programs.

Problems have arisen, too, in connection with 
the criteria to be used by the Council in the selection of members. There have been instances in which men of recognized merit as teachers present but limited evidence of productivity as investigators. Often, these are men of outstanding ability, highly esteemed by their colleagues in academic circles, and it is a ticklish matter to exclude them from membership on the basis of their limited research activities. Another delicate consideration sometimes arises in connection with the academic affiliation of a nominee. There is an inevitable tendency to regard a candidate from an outstanding institution with greater favor than a candidate from a less well known school, primarily because the standards against which the former has been measured and the men with whom he has worked are a known quantity to the members of the Council. On the other hand, there have been vigorous debates over nominees from lesser institutions who, although sometimes less qualified on an "absolute" scale, have made significant achievements relative to the conditions under which they have worked. Decisions in such cases involve the more fundamental problem of how the Society can best promote "the cultivation of clinical research"- whether by recognizing the prior attainment of high standards or, in some cases, by fanning a spark of interest and ability in research existing in the "outlying regions" where less favorable circumstances prevail.

The question of expanding the program beyond the traditional single session, single day limits has been one of the most vigorously contested issues in the Society's history. In 1921, a two day session was considered and rejected; in 1927, the division of the meeting into three sections was considered and rejected; and in 1932, an evening session was considered and rejected. Thereafter, the issue raised its troublesome head with almost annual regularity. No sooner was it disposed of at one meeting than it would be reintroduced at the next and a new proposal for its solution subjected to a repeated vote. Probably no other problem has received such persistent attention from the membership at large-it seems to be one of the few issues which was handled as often on the floor of the business meetings or through the mails as it was in the sessions of the Council.
The advocates of change won out for the first time in 1934 when approval was given for a trial departure from tradition for the following year. Thus, the twenty-seventh annual meeting of 1935 was divided into two simultaneous scientific sessions with 22 papers scheduled for presentation in each. The success of this innovation was discussed at a general business meeting following the completion of the double program and a variation adopted for the following year. The 1936 meeting, thus, consisted of a general morning session and a double afternoon meeting. This plan, actually, provided no solution to the problem of an oversupply of papers for only nine were scheduled for each of the three half day sessions and the total of 27 thus presented was no greater than that normally appearing on single session programs.

After these two years of experimentation, however, the Society hastened to retreat. In 1936, "after mature consideration of the question," it was the opinion of the Council that "the interests of the Society could best be served by a return to the single session program." What these "best interests" were is summed up in the following views expressed by Dr. Paul (38) :

In retrospect, at least, I believe that the Society's strength was enhanced by the fact that it took upon itself the task each year to pick the best from a long list of titles and to condense their presentation into a single day. This was not the practice of other societies which went in for quantity rather than quality. It meant that sometimes about four times as many titles were submitted to the Society as were actually presented and loud was the complaint from some that good material was not being heard. However, in the long run this seemed to react favorably and it never seemed to deter the membership from submitting its long list of titles. It also served to raise the stature of the meetings. To be chosen as a speaker at the American Society for Clinical Investigation has become an honor of growing importance.

Although it was such considerations as these which led to the 1936 Council decision, a final settlement to the problem had not been achieved. Criticism of the selection of papers was sometimes quite vehement, presidents being accused, on occasion, of biasing the programs in the direction of their own scientific interests or of taking considerations other than merit alone into account. Dr. Paul recalled "a storm of protest" one year 
when the president announced that he had leaned heavily on the geographical distribution of authors in making his choices. Dr. John P. Peters, whose voice was often raised and usually respected in the Society's decisions on policy was especially vociferous in disapproving this particular innovation. Thus, the debate went on. In 1939, a new Council voted to resubmit the type of meeting question to the Society, urging by a five to one margin that the double session program be reinstated. Opinion among the general membership, however, was more evenly divided. At the general business meeting, the Society voted to retain the status quo although the double session plan lost by only seven votes $(47-40)$. In 1940, the Council again took up the question, this time in response to a letter from Dr. Peters urging reconsideration. The matter was resolved by conducting a post card ballot, among active members only, in time to permit decision as to the form of the 1941 meeting. A similar referendum was held prior to the 1942 meeting and on both occasions a plurality favored a half or whole day double program at the discretion of the president after inspection of the quality of the abstracts submitted. With this mandate from the membership, Presidents William B. Castle (1941) and William S. Dock (1942) scheduled double morning and single afternoon sessions at which, in each year, a total of 45 papers was presented.

World War II twice disrupted the orderly progression of annual meetings-in 1943 and 1945. In response to a memorandum from the Office of Defense Transportation requesting the cancellation of meetings during 1943, President Eugene M. Landis wrote for clarification of the Society's status, outlining the nature of its meeting and the expected attendance. A reply from the Director of the Division of Traffic Movement indicated that the final decision was up to individual organizations themselves, but that unless the meeting had a direct bearing on the war effort, its omission would be greatly appreciated in light of the need to alleviate the burden on transportation facilities. The Council members were unanimous in their decision to cancel the 1943 sessions. Similar considerations applied in 1945. In both years, Council members met in Cleveland, Ohio, to carry out such routine functions as the nomination of officers and new members and to transact other necessary business. Decisions, along with the minutes of the meetings, were transmitted to the membership for approval by mail.

These war years were thus a kind of interlude in which little significant action could be taken and in which pressing problems were temporarily shelved. 


\section{THE TEMPERING OF TRADI- TIONS, 1946-1959}

If clinical research activity had boomed in the 1920's and 1930's, it exploded in the years following World War II. In the interval between 1945 and 1955 alone, the number of physicians trained in clinical investigation increased tenfold. The funds available for medical research likewise multiplied at a rapid rate, in large part due to the entry of the federal government into the support of scientific activities on a massive scale. According to Dr. W. Barry Wood, Jr., president of the Society in 1952, there are some who believe that the postwar growth of clinical investigation has actually been too great in proportion to the growth of research in the basic sciences (although the latter has also increased tremendously). This point of view stands in striking contrast to that professed by Dr. Meltzer in 1909 and serves to indicate the amazing changes which have taken place in the status of his "new science."

The effects of such changes on the Society's already swollen membership ranks need not be elaborated. Suffice it to say that when the Atlantic City sessions were resumed in 1946, many of the same internal and external tensions were still present, but in the postwar years they have taken on new and complicating aspects. Not only, for example, did the Society have to decide what to do about a mounting number of nominees. In addition, it had to decide what to do about an unprecedented number of spectators. The fundamental conflict between high standards and more extensive services manifested itself anew in such bitterly-disputed decisions as the move to the Steel Pier Theater and in the continuing debates over membership and programming policies. In some matters, the decisions of an earlier day were reaffirmed. In others, it was necessary to modify traditional policies in accordance with the demands of changing times.

After lying dormant for a number of years, the "type of meeting" question began to reappear on Council agendas after 1949. No longer, however, was the central issue one of single versus double session programs. Rather, discussions revolved about the possibility of extending the program to more than one day and of doing so in cooperation with the "senior" and "junior" organizations, the
Association of American Physicians and the American Federation for Clinical Research.

It is interesting to note that in 1939 and 1942 Society members had rejected firmly the third alternative of a two day meeting. It was this alternative, however, which received major consideration in the years following World War II. Thus, in 1949, in view of the Society's traditionally close relationship with the Association of American Physicians, the Council instructed the incoming president to confer with the incoming president of the Association regarding the possible integration of the two programs. If such consultation actually took place it apparently came to nothing and is not mentioned subsequently in either the Society's records or the Transactions of the Association. Three years later, however, agreement was obtained on a proposal to extend the meeting to a day and a half, provided "suitable arrangements could be made with the Association." That organization's Council agreed to the change under which the Association would have met all day Monday and on Tuesday morning; the Society, Tuesday afternoon and all day Wednesday. Fortunately or unfortunately, however, the plan never got beyond a tentative stage. When it was discovered that the Haddon Hall Hotel could not accommodate Society members on Wednesday night, the traditional single day meeting was restored to the traditional Monday where it has remained ever since.

Two years ago, in 1957, a special committee consisting of Drs. R. V. Ebert, S. J. Farber, J. D. Myers (chairman) and L. A. Rantz was appointed to consider once again the form of the annual meeting, and this time a major change was effected. According to its report, "The committee decided that the time had come when there should be sectional meetings in our program, that is, meetings of appropriate sections of the general field of clinical investigation in medicine." These meetings were to be in addition to the usual general session and were to begin in 1958. They were to be held on the Sunday afternoon preceding the Society's regular session, thus running concurrently with the regular meeting of the American Federation for Clinical Research. The committee met with representatives of the Federation and invited that organization to join with the Society 
in sponsoring the sectional sessions, although it was made clear that the Society planned to undertake the project alone if necessary. The invitation to joint sponsorship was accepted by the Federation, details were worked out by the presidents of the two organizations, and in 1958 the cooperative sectional meeting plan was inaugurated. Repeated in 1959, the sections are no doubt here to stay and represent, it would appear, a partial solution to the long-standing problem of accommodating a greater number of papers and a happy compromise in the controversy over a specialized versus general interest program.

Although the question of increasing membership was aired by the Council in 1950 and 1951, stimulated on both occasions by letters from Society members urging expansion, no changes were made until 1952. In that year, the Society adopted three amendments which 1) increased the annual quota on new members to 35 (previously 25 ) or the number equal to the number of retiring active members, whichever was larger; 2) allowed members to request transfer to emeritus standing after five, rather than 10 , years of active membership; and 3) made the nonpayment of dues for two, rather than three, successive years a cause for forfeiture of membership. To date, these are the last changes which have been made in membership policy. Thus, although the Society has made provision for slight increases in size, the guiding principle has remained that of keeping the organization small and highly selective. Addressing the Society in 1957, President Stanley E. Bradley presented an eloquent argument in support of this position (39). Tracing the evolution of "the tradition of scientific critique" through the 300 year history of learned societies which had been "formed to defend and exploit the new (scientific) method," he discussed in particular the Royal Society of London, showing how its influence had waxed and waned as it had alternated between maintaining standards of the highest excellence, allowing them to fall, and again restoring them to a high level. Then he continued:

The parallels between the story of the Royal Society and our own need not be belabored. We, too, are faced with the problems posed by an unsettled membership policy, by an ill-defined relationship to other groups, and by pressure for expansion.... Our Society also has stood for quality, for the highest possible standards of excellence in membership, in the Journal and in the papers presented before this meeting. ... No standard that lacks divine sanction is readily acceptable; jealousies, resentments, fears, a host of varied considerations combine to raise up an active opposition to it. . . C Criticism of the Society is especially acrid in connection with the choice of new members. In eight years of work on the Council ... I can say with pride that I have never seen any consideration other than merit take first place though geographical distribution is often urged upon us.... More recently there has been pressure to increase the membership on the assumption that the number of new members should be determined by the number of men nominated. The history of the Royal Society shows the fallacy and danger of this assumption. If we wish to allow for the growth of the research establishment in this country, we might gear membership to the number of workers listed in American Men of Science, or better yet, to the number of subscribers or contributors to the Journal of Clinical Investigation. Certainly the number nominated is a poor criterion of anything but the prestige of the Society.

The "prestige of the Society" gave rise to another problem in addition to the growing number of nominees-the problem of the growing number of nonmembers attending the annual meetings. Acting on the basis of letters from a number of members urging that a larger meeting hall be found, the Council, in 1950, initiated what is quite possibly the most radical change in the entire history of the Society-the move from the relatively small chambers of the Traymore and Haddon Hall Hotels to the Atlantic City Steel Pier Theater, a huge auditorium. The move was recommended on a trial basis for 1951 and a short Council meeting following that year's experimental sessions resulted in a decision to return in 1952, a decision which has been followed ever since.

The official records of the Society contain only two references to the change-the initial decision is set down in a three sentence paragraph in the minutes of the 1950 meeting of the Council and two additional sentences in the 1951 records suffice to indicate that the change was to be permanent. Despite this secretarial brevity, however, such a move had been under consideration for some time prior to 1950 (although probably not before the end of the war) and was not greeted with anything resembling the universal docility which the records alone might lead us to surmise. Rather, in the words of Dr. Wood, who served on the Council between 1947 and 1949, "The move to the 
Steel Pier was made reluctantly, only after the pressure of the audience made it necessary." The decision, when it finally came, Dr. Wood pointed out, was the outcome of a struggle between proponents of two opposing views: those eager to maintain the type of meeting in which informal discussion was possible, and those who urged that their "inspiration value" be extended to a wider audience. In the end, the latter view won out but, according to Dr. Wood, "it took quite awhile for this to break through."

Traditionally, although both members and guests had increased in number, the Society had adhered to the view that its meetings were the occasion not simply for the presentation, but for the exchange, of ideas relating to scientific work. True, time for discussions had undergone considerable trimming since the early days. But the prevailing atmospheric conditions at meetings had been conducive to easy and informal give-andtake. Although intimacy was relative, it had been fostered by the closer quarters of such meeting places as the Viking and Vernon Rooms of Haddon Hall. The migration to the Steel Pier reflected the fact that these earlier meeting places had been outgrown, but it also symbolized a new conception of what the annual meetings should represent. The attractiveness of the Society's meetings carried with it a degree of "noblesse oblige," and many members began to express the opinion that the organization had a direct responsibility, not just to its members, but to the large audiences and particularly to the medical students and house officers who made the annual pilgrimage to Atlantic City and derived from the meetings renewed inspiration for their own work. One of the stated objects of the Society, as set forth in the constitution, was, and remains, “. . . the diffusion of a scientific spirit among its members." In this connection, it is interesting to note that at the charter meeting in 1908, Dr. Theodore C. Janeway had moved to delete the phrase "among its members" from the original draft. His motion had failed for lack of a second, but perhaps in 1950 the Young Turks came back, in deed if not in word, to what Dr. Janeway had had in mind. One of their objects, thenceforth, was to be ". . . the diffusion of a scientific spirit" beyond the limits of the membership.
Be that as it may, opinion on the wisdom of the Steel Pier move remains somewhat divided, although most members seem to have accepted it fatalistically, if not exactly enthusiastically, as "inevitable." There seems to be general agreement that present day meetings are "different" but there are, on the one hand, those who say that the move has "spoiled the meetings" and, on the other, those who say it has merely "changed" them. Many who are most vociferous in their denunciation of the change end their diatribe against the Steel Pier with the concession that it does have the advantage of allowing the youthful audience- - "those who need it most"-to hear the results of "the best work done each year in clinical research." Whether this advantage negates much else that was formerly of value in Society meetings seems still to be an open question.

Older members, who look back to the days when discussions were "hot and good," bemoan the loss of intimacy wrought by the change. Back in the '20's and '30's, they say, the Society was "like a family group" in which relations were friendly but no one hesitated to say what he thought.

"Now that they've moved to that Steel Pier," one former president lamented, "no one has nerve enough to get up and give the speaker hell. After all, you can't call a member of your family a name in front of thousands of people!"

Another emeritus member, also a past president, was quoted by President Robert H. Williams (40) at the 1955 meeting as follows: ". . . The program and the Steel Pier are terrible," said he. "I do not see why these meetings should be the occasion for carnivals, in which nonmembers are ten times as numerous as members."

But there are ex-presidents lined up on the other side as well. "Discussion is certainly less informal," one of them admitted readily. But, noting that "the Steel Pier is very different psychologically," he questioned whether speaking before a large, impersonal audience where one is hardly aware of anything but a vast sea of faces is really more difficult than speaking before an intimate-and critical-group of personal friends. Another ventured the opinion that discussion varied more from year to year, and always had, 
than as a function of such external factors as the size of the audience or the meeting hall.

Dr. Williams' 1955 survey (he had conducted an informal poll among active members regarding their opinions on a variety of Society policies) (40) revealed some further facts in the controversy. Twenty-nine members (of approximately 100 who had replied to his letter) indicated complete satisfaction with the programs. On the other hand, 47-nearly half-of the replies he had received contained the complaint that discussion was inadequate. This shortcoming was attributed, among other reasons, to the size of the crowd and the embarrassment associated with speaking before it. ${ }^{7}$ Not only the scientific program, but the type of personal contact which had characterized Young Turk gatherings of an earlier day had suffered in the opinion of many. Typical comments read by Dr. Williams (40) were these:

... As the crowds at Atlantic City have become so very vast, it has become difficult to meet anyone except by appointment, and often then, only for brief periods of time.

Or :

I visualize (the Society) originally as being a rather small club which had social function and a high scientific standard ... It is no longer a social club in any sense of the word.... It is with the greatest difficulty that I am able to remember who is a member and who is not.

And thus, the controversy continues. Despite opinion as to the merits of the Society's newest meeting hall, it does seem in many ways to represent a satisfactory compromise in the old conflict of standards versus services. For if, as seems apparent, the Young Turks have decided against any significant easing of membership restrictions, they appear to have found in the larger capacity of the Steel Pier Theater a means of extending their services to nonmembers without sacrificing the high standards required for election.

Preliminary rumblings of pressure for another kind of move were heard in 1954 when the Coun-

${ }^{7}$ Other reasons given for dissatisfaction with meetings were as follows: Talks too complex or technical, 21 members; talks not clinical enough, 12 ; 10 minutes too short, 21 ; a one-day program too short, 13 . Correspondingly, such reasons as inability to understand talks and pressure of time were also cited as factors contributing to inadequate discussion. cil considered the possibility of meeting in a location other than Atlantic City. In a statement prepared for presentation at the business meeting, the Council members pointed out that "the practice of holding every meeting in the same city involves certain disadvantages and inequities to a large segment of our membership and guests" and recommended that a move be given "serious consideration." In his presidential address that year, Dr. Carl V. Moore included a similar plea (33):

The time has come, it seems to me, for us to recognize the "American" in our name, to meet in other sections of the country as well as here. ... so that the splendid influence of these sessions can be spread over a broader section of the country. Men have discussed such a plan on the Boardwalk for years; councils have debated it; the time is ripe for one of your presidents to recommend it from here.

Dr. J. D. Myers was appointed to represent the Society in consultation with representatives of the Association of American Physicians and the American Federation for Clinical Research regarding the feasibility of such a move. This committee's conclusion, reported in 1955 , was that "for the forseeable future" it was advisable to remain in Atlantic City. The Council minutes state, however, that "the Society will continue active exploration of the possibility of meeting occasionally in a city other than Atlantic City." There is no official indication that this intention has been carried out and, to date, neither the Society nor its comrade organizations have made any overt move in the direction of another city. However, the 1954-55 consideration of such a possibility reflects certain changes in the modern day makeup of American investigative medicine and their relation to the Society. With the postwar expansion of research activity, numerous new organizations representing various subspecialties of the field have likewise sprouted. As a result, the Atlantic City meetings, which formerly were considered the high point of the year by clinical investigators, have become, as Dr. Wood put it, "somewhat diluted." Their quality has not been impaired, but against the background of a yearround succession of meetings taking place all across the nation the Atlantic City sessions no longer stand out so distinctly. Dr. Wood pointed out, furthermore, that the geographical center of research activity seems to be shifting away from 
the Eastern seaboard. The Society's composition from a geographical point of view was illustrated by a diagram presented by Dr. Moore (33) in connection with his 1954 address. Dividing the nation vertically into three sectors, he gave the following figures on the distribution of members as of 1954 :

$\begin{array}{lcc} & \text { Active } & \text { Emeritus } \\ \text { East Coast } & 176 & 249 \\ \text { Midwest } & 62 & 107 \\ \text { Far West } & 30 & 29\end{array}$

Although the 1955 decision to stay in Atlantic City was based on the fact that it was still the most convenient location for the majority of the members of the three associations, its disadvantages are becoming increasingly apparent and may portend departure from still another timehonored tradition in the future.

Another of the Society's traditional positions coming up for re-examination after the war was its attitude toward medico-political problems. Perhaps the most striking change in the overall picture of clinical investigation in this country since about 1940 has been the growth of federal support for research activities. With governmental agencies offering plums for distribution. there has been a markedly increased tendency on the part of many national medical organizations to keep a watchful eye on the federal hand that feeds them. Although the Society has usually stuck to its traditional scientific preoccupations, it has been forced, increasingly, to consider its proper attitude toward certain political questions.

Except for two resolutions which, as previously noted, were adopted in 1917, the Society as an organization had followed a policy of "nonintervention" in the politics of research. preferring to stick to the substance instead. The general feeling seemed to be that there were more appropriate channels than the Society through which individual members could act regarding matters of national policy and that nothing should be allowed to detract from the essential purpose of the annual meetings-the consideration of scientific work. This viewpoint is illustrated by a Council decision made in 1938. In that year, communications from a number of groups and individuals requesting permission to submit various resolutions to the Society had been received. The exact na- ture of these resolutions is not on record, but permission to present them was denied, not on the lasis of their content, but because "in view of the very limited time for our meetings, the consideration of such subjects by the Society as a whole (is) impractical, and ... any recommendation on these matters (is) outside the province of Council."

Such questions did not come up again until after the war. In 1950, Dr. John Dingle, delegate to the National Research Council, met with the Society's Council to discuss the advisability of the Society's acting as a body in expressing views on such subjects as federal support of research. Correspondence between Dr. Dingle and Dr. Thomas Hale Ham, then presilent of the Society, had been circulated among the members and some 75 letters received in response. After discussion, the Council concluded that many of the political issues at stake could be handled most effectively through the Society's National Research Council delegate and, to assure a closer working relationship, it was recommended that future delegates sit with the Council and present an annual report for Council's consideration. However, the minutes read, "Beyond this, it was not thought advisable to make any major change in policy of the Society. Individual members can act through other societies, their own institutions, or boards and committees on which they serve."

Similar considerations prevailed in 1955 when Delegate Thomas Hunter's report included a request from the National Research Council that the Society support a National Research Fellowship. The records state that after some discussion, "Council concluded regretfully that the Society was not in a financial position to support such a fellowship, but it was felt that the Society through its membership was providing considerable support and guidance to the research activities in which the NRC is interested."

On both of these occasions, the issue of taking stands on political policy questions was intertwined with the somewhat more diffuse issue of the Society's relationship to the National Research Council. This organization's membership consisted of representatives of "constituent societies," members-at-large, and members of the National Academy of Sciences. Since 1917, the Society 
had maintained a representative, but his attendance at the annual meetings of the NRC's Division of Medical Sciences had apparently amounted to little more than a formality. In 1948, however, with the NRC coming into greater prominence because of its responsibility in handling federal funds, the whole question of the rather ambiguous NRC-constituent society relationship came up for reappraisal. A large share of the credit for the initiation of this reappraisal apparently goes to Society Delegate Dingle, but his efforts were to little avail. Attempts to work out a more precise definition of the role of member societies and their delegates soon bogged down at the various levels of NRC bureaucracy and the Society's rather exasperated attitude toward the whole issue was summed up in 1951 by Delegate W'alsh McDermott in his report to the (Society's) Council:

Under the present system, the Society representative is in effect no more than an emblem on display at the (National Research Council's) annual meeting to indicate the good faith of the Society. Accordingly, two possible courses of action could be considered: (1) continue the presentation of the Society representative as an emblem ... on the assumption that at some future date the role of constituent societies will actually be redefined or (2) have the ASCI representation handled by one of the numerous members of the Society who would inevitably be members of the executive committee of the Division of Medical Sciences. .. The additional effort necessary for a member of the executive committee to serve also as a Society representative would be trivial.

The Society's delegate, as of 1959, is still an "emblem" and clarification of his role still wanting.

Although Society officialdom remained firm in its traditional "hands off" policy where matters of state were concerned, there was one occasion on which the membership rose up to petition the government. In 1954, Drs. T. S. Danowski and Eugene A. Stead moved at the Society's business meeting to circulate a statement for signatures. Critical of a United States Public Health Service policy on the allocation of research funds, the petition read as follows:

We, the undersigned members of the American Society for Clinical Investigation, are greatly perturbed by your recent announcement that competent investigators have been deprived of United States Public Health Service research funds because of allegedly derogatory information in their files. We recognize the necessity for security clearance of individuals engaged in classi- fied research. However, it is our firm belief that awarding grants for unclassified research on any basis other than the value of the project and the competence of the investigator endangers not only scientific freedom but also the basic foundations of our way of life.

The petition was, of course, a part of the general cry of consternation being raised at that time over the "un-American activities" of Senator Joseph McCarthy and his followers but Society members had, in addition, a more personal motive for their action. Government "punishment" of individuals on the grounds of alleged disloyalty had struck close to home in the case of several Society members-most prominently, in the case of Dr. John P. Peters. In addition to being denied the use of federal research funds, Dr. Peters was dismissed from membership on a Study Section of the National Institutes of Health's Division of Research Grants and Fellowships on anonymous and undisclosed charges of disloyalty (41). According to close friends and associates, the charges were completely unfounded and Dr. Peters could have accepted his dismissal quietly. His membership on the Study Section was due to expire shortly (he had already attended the last meeting of his term at the time of his dismissal). But he chose, instead, to dispute the Loyalty Board's decision. His case was carried to the United States Supreme Court and, although he was cleared personally, the Court refused to rule on the principle which Dr. Peters had hoped to establish: the unconstitutionality of loyalty proceedings in which the accused was not allowed to confront and cross-examine the witnesses against him.

Thus, it was in Dr. Peters' defense that Society members arose in affixing their signatures to the 1954 petition and it was one of his students, Dr. Danowski, who led the fight. The motion to circulate the statement was approved without dissent and, at the meeting the following year, it was reported that a majority of the active members had approved it. It had subsequently been submitted to the Department of Health, Education and Welfare. Replies from Department officials expressed appreciation to members of the Society for making known their opinion and advised them that the "problem was under continued study."

Federal activity, as might be expected, has 
prompted commentary by Society presidents. In an address entitled "Biological Beachheads" delivered at the first postwar meeting, in 1946, Dr. Thomas Francis, Jr., expressed concern over the possible effects of various legislative proposals for the mobilization of medical research forcesfear that coordinated study projects organized along the lines of the atomic bomb research groups would stifle original thinking; that any federal research agency, by the very nature of the administrative principles of a large organization. would tend to be "founded on orthodoxy" and to breed "conformity with accepted opinion" (42). Fears such as these were prevalent among s ientists in the immediate aftermath of the war, but in a sense they were really old concerns under a new guise. It is interesting to recall, for example, Dr. Loeb's denunciation of the "research project" in 1936 (27) and to note that similar fearsparticularly as regards the "strings" which might be attached to funds-were expressed with regard to private sources of support when these had come into prominence at a somewhat earlier date (11).

One facet of federal support which sometimes poses peculiar problems is that of Congressional preference for research leading to tangible progress on the problems of specific diseases. This has resulted in the channelling of a large share of public funds into "categorical" research, a point on which Dr. A. McGehee Harvey commented in his 1956 presidential address (43). Dealing with the role of the university medical centers in the training of investigators, Dr. Harvey traced some of the academic shortcomings to the financial straits in which many departments found themselves. One major difficulty, he pointed out, was that of the funds available too many were earmarked for specific research and could not be used for general operating expenses, the point at which many of the university departments were running short. To remedy the situation, Dr. Harvey made this suggestion:

The Federal Government might adopt in the future an overall policy of more realistic reimbursement of overhead expense to grantees such as it does to contractees of Federal research funds. A greater percentage of the Federal money for general support of research and research training in University centers and less of the total for categorized research is highly desirable.
On other subjects as well, postwar presidents have continued to fill the role of perceptive observer or unsparing critic. Since 1946, the topics to which they have addressed themselves have been diverse, ranging from the lessons of personal experience to problems and opportunities in medical academia, from Society policies to the contemporary status of clinical research. The specific problems of today add unique dimensions, but the general areas of concern which drew comment from an earlier generation of Society presidents receive renewed consideration from their present day counterparts.

It is this same combination of continuity and change which has characterized the evolution of the Society to the present day. With respect to its internal affairs, tradition, as we have seen, has been tempered in the ever-tended fires of controversy and, although changes have seldom been radical, the policies inherited from the past have undergone gradual modification in response to the needs of the present. Less responsive than some would have it, more so than others, the Society has evolved its policies through a continual restriking of the balance. The prestige which it enjoys today can be attributed in large part to the long-standing tradition of high standards which it has maintained, at times in the face of vigorous assaults from within and without. At the same time, present generation Young Turks have not allowed their hands to be tied by uncompromising adherence to policies established by their predecessors. Through such measures as the extension of its program in cooperation with the American Federation for Clinical Research and the expansion of its meeting capacity, the Society has demonstrated a necessary flexibility. Though the wisdom of these moves may be disputed, they attest to the continuing round of conflict and compromise which seems essential to the future health of any organization.

In a broader sense, however, the history of the Society is constituted not in the evolution of policies but in the overall development of clinical investigation which has accompanied, and interacted with, its growth. The real measure of its success lies in the extent to which the objects laid down by its founders have been advanced. In this respect, the Society has a proud past. In 1957, 
50 years after the Society was born in the minds of a small group of men on the Boardwalk, Dr. Bradley (39) presented the following testimony to the achievements which had taken place during the course of its lifetime:

To the best of my knowledge, no conscious plan was ever laid down to attain our Constitutional objectives, but the size and interest of the audiences we are privileged to entertain each year suggest that the Society may have teen successful in spite of itself. Medical education has undergone an extensive revision in the years since the first meeting and there is good reason to believe that many members played a major role in the process. In time the triumph of the ideals to which these men subscribed gave lustre to the Society. The standards they established in selecting members reflected great credit upon and gave distinction to the fact of membership itself. The Journal benefitted as a result of the conspicuous quality of the papers it was able to attract. The conscious emulation of the accomplishments of the founding members has done much to promote "the cultivation of clinical research by the methods of the natural sciences" throughout this country and to encourage "the diffusion of a scientific spirit."

Of even greater importance has been the change in the practice of medicine during these years. There is little doubt that now science and medicine are closely blended, a result born of dire and urgent necessity. In no other group of professional workers is the scientific attitude more vital or more meaningfully a matter of life and death. Practice today is truly clinical investigation, demanding at once a vigilant critique, a full understanding of the human situation and a knowledge of fundamental scientific techniques. As it strives to assist in maintaining a high standard of excellence in clinical research, the Society fully serves the ends for which it was founded.

It would seem most fitting to conclude the story of the Society's first half century by turning toward its second with the words of this year's president, Dr. John Luetscher (44), spoken on the fiftieth anniversary of the Society's first annual meeting :

If the Society is to progress toward the promise and goals of its founders, their lively pioneer spirit must neither be drowned in excessive numbers nor immobilized in outdated tradition. Let us look to the next 50 years with a welcome to many more of Dr. Meltzer's "brainy young men" and to their fresh ideas and new programs for this ever youthful Society.

\section{REFERENCES}

1. Longcope, W. T. Dr. Meltzer's influence on the origin and ideals of the Society for Clinical Investigation. Proc. 13th Ann. Mtg. (May 9, 1921). Chicago, Press of the American Medical Association, 1921.

2. Tileston, W. Personal communication.

3. Edsall, D. L. Letter to Dr. C. Sidney Burwell. Feb. 5, 1934.

4. Longcope, W. T. Letter to Dr. C. Sidney Burwell. Feb. 20, 1934.

5. Robinson, G. C. Letter to Dr. C. Sidney Burwell. Jan. 2, 1934.

6. Cole, R. Medical societies and medical progress. J. Mich. med. Soc. 1941, 40, 19.

7. Lusk, G. The Harvey Seciety. Science 1930, 71, 627.

8. Pratt, J. H. Letter to Dr. C. Sidney Burwell. Feb. 8, 1934.

9. Rowntree, L. G. Amid Masters of Twentieth Century Medicine. Springfield, Charles C Thomas, 1958.

10. Robinson, G. C. Adventures in Medical Education. Cambridge, The Commonwealth Fund-Harvard University Press, 1957.

11. Shryock, R. H. American Medical Research. New York, The Commonwealth Fund, 1947.

12. History of the Interurban Clinical Club, 1905-1937, D. Riesman, Ed. Philadelphia, John C. Winston Co., 1937.

13. Means, J. H. Experiences and opinions of a fulltime medical teacher. Perspectives Biol. Med. 1958, $2,127$.

14. Cohn, A. E., and Cole, R. in Addresses made at the dinner in honour of Doctor Cole on the occasion of his retirement as Director of the Hospital of the Rockefeller Institute for Medical Research (April 30, 1938). New York, The Rockefeller Institute, 1938.

15. Minot, G. R. David Linn Edsall. Trans. Ass. Amer. Phycns 1946, 59, 9.

16. Bordley, J., III. Warfield Theobald Longcope. Trans. Ass. Amer. Phycns 1953, 66, 9.

17. Rackemann, F. M. Joseph Hersey Pratt. Trans. Ass. Amer. Phycns 1956, 69, 24.

18. Cole, R. Personal communication.

19. Robinson, G. C. Personal communication.

20. Shapiro, J. S. Modern and Contemporary European History (1815-1952), 1953 ed. Cambridge, Houghton Mifflin Company, 1953, p. 479.

21. Flexner, A. Medical Education, A Comparative Study. New York, The Macmillan Company, 1925.

22. Bloomfield, A. Personal communication.

23. Meltzer, S. J. The science of clinical medicine: What it ought to be and the men to uphold it. J. Amer. med. Ass. 1909, 53, 508. 
24. Austin, J. H. A brief sketch of the history of the American Society for Clinical Investigation. J. clin. Invest. 1949, 28, 401.

25. Morison, S. E., and Commager, H. S. The Growth of the American Republic, 4th ed. New York, Oxford University Press, 1950, vol. II, pp. 377-78.

26. DuBois, E. F. What should we do with a Harvey or a Laennec? Science 1927, 65, 587.

27. Loeb, R. F. Comments on clinical investigation. Science 1936, 83, 423.

28. Rowntree, L. G. The spirit of investigation in medicine. Science 1921, 54, 179.

29. Cohn, A. E. Purposes in medical research: An introduction to the Journal of Clinical Investigation. J. clin. Invest. 1924, 1, 1.

30. Starr, I. Personal communication.

31. Blake, F. G. Clinical investigation. Science 1931, 74, 27.

32. Paul, J. R. Clinical epidemiology. J. clin. Invest. 1938, 17, 539.

33. Moore, Carl V. Presidential address. J. clin. Invest. 1954, 33, 912.

34. Harrison, T. R. Presidential address. J. clin. Invest. 1939, 18, 469.
35. Starr, I. Functions and dysfunctions of learned societies. J. clin. Invest. 1940, 19, 765.

36. DuBois, E. F. Elimination of worthless drugs (president's address). Trans. Ass. Amer. Phycns 1939, 54, 3.

37. Dock, W. S. Personal communication.

38. Paul, J. R. Personal communication.

39. Bradley, S. E. The tradition of scientific critique. J. clin. Invest. 1957, 36, 866.

40. Williams, R. H. Activities of the American Society for Clinical Investigation. J. clin. Invest. 1955, 34, 907.

41. Paul, J. R., and Long, C. N. H. John Punnett Peters, 1837-1955. Biographical Memoirs 1958, 31, 347.

42. Francis, T., Jr. Biological beachheads. J. clin. Invest. $1946,25,906$.

43. Harvey, A. McG. The individual in medical research and the role of the university medical center in his training. J. clin. Invest. 1956, 35, 683.

44. Luetscher, J. A. Observations on growth and development of clinical investigation. J. clin. Invest. $1959,38,981$.

PICTURE CREDITS

Pages 1828-1830: (S. J. Meltzer, R. Cole), courtesy of Mr. Eugene H. Kone, The Rockefeller Institute; (J. A. Capps), courtesy of Dr. Wright Adams, Department of Medicine, The University of Chicago; (H. A. Christian, D. L. Edsall, and J. H. Pratt), courtesy of Mr. Herbert Shaw, University News Office for the Medical Area, Harvard University; (W. T. Longcope), from the Department of Medicine, College of Physicians and Surgeons, N. Y., courtesy of Dr. H. Houston Merritt; (A. W. Hewlett), courtesy of Dr. Louise Hewlett and Mr. William R. Hewlett and of Dr. Robert H. Alway, Dean, School of Medicine, Stanford University, Cal.

Page 1832: (Top) photograph by Fred Hess, courtesy of the Management, Hotel Traymore, Atlantic City, N. J.; (bottom) reproduced from Willard's of Washington: Garnett Laidlaw Eskew, (New York, Coward-McCann, Inc., 1954) with permission from the publisher.

Page 1833: (Bottom) courtesy of the Management, Hackney's Shore Dinners, Atlantic City, N. J. 


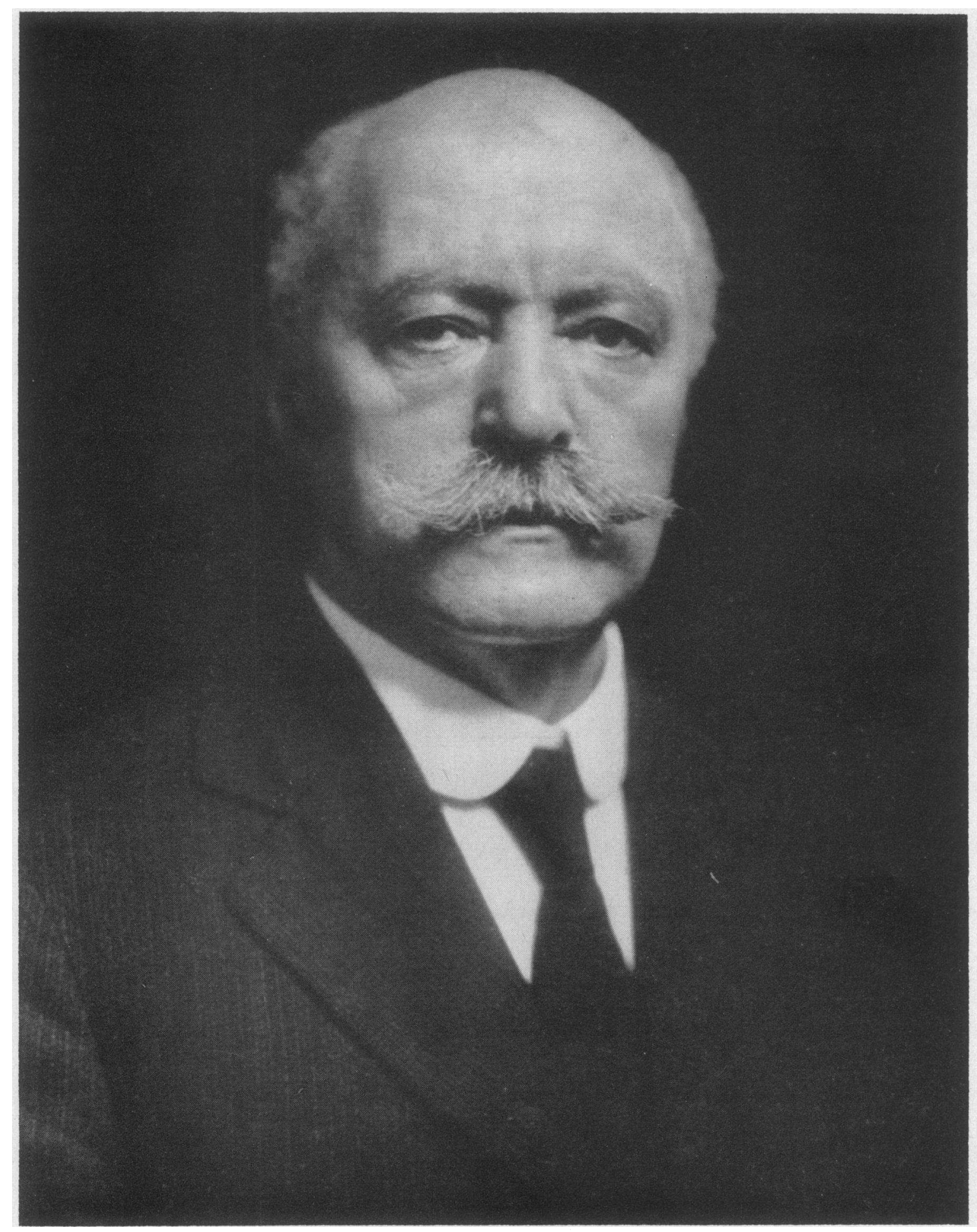

SAmuel J. Meltzer

The initial suggestion for the founding of the American Society for Clinical Investigation came from Dr. Meltzer in June, 1907, and his was the guiding influence among the group of younger men who laid the actual plans for its organization the following year. His views regarding "what the science of clinical medicine ought to be" formed the basis of the ideals for which the Society has stood during its 50 years of existence. To Dr. Meltzer, therefore, goes the major share of credit for the Society's establishment. Photographs of the eight other "first Young Turks" who, with Dr. Meltzer, comprised the Society's founding committee, appear on the following pages. 


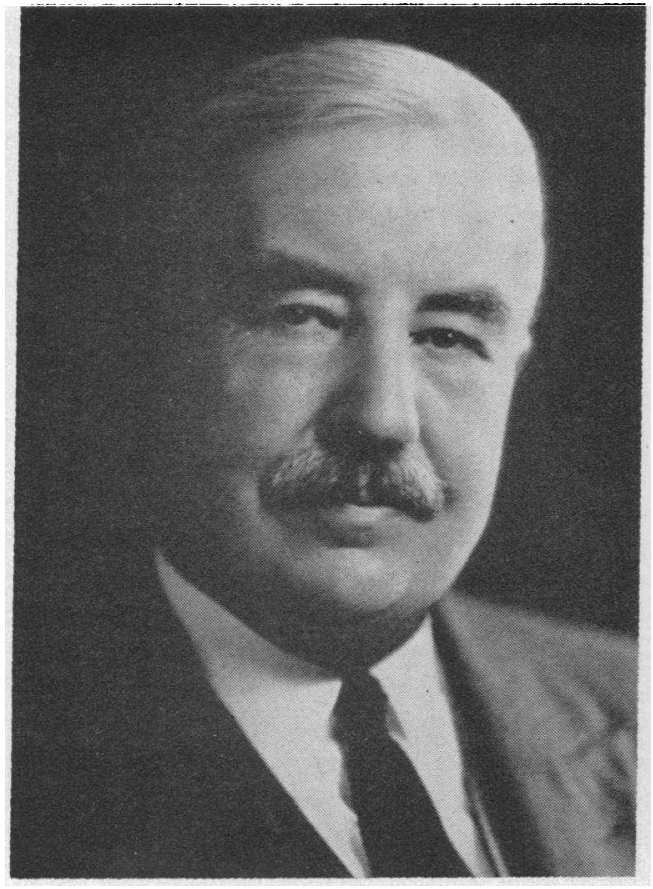

Joseph A. CAPps

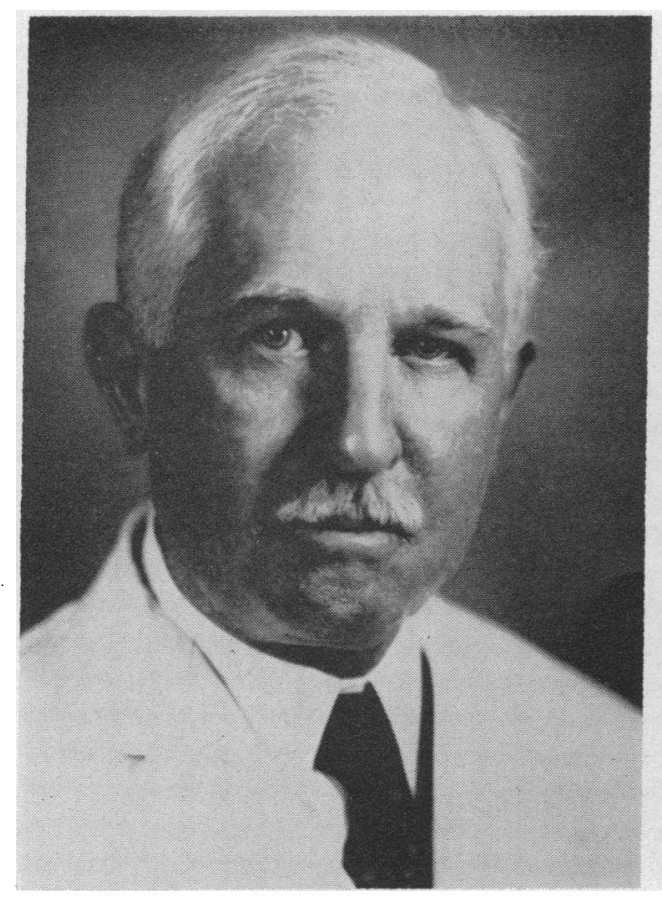

Rufus Cole

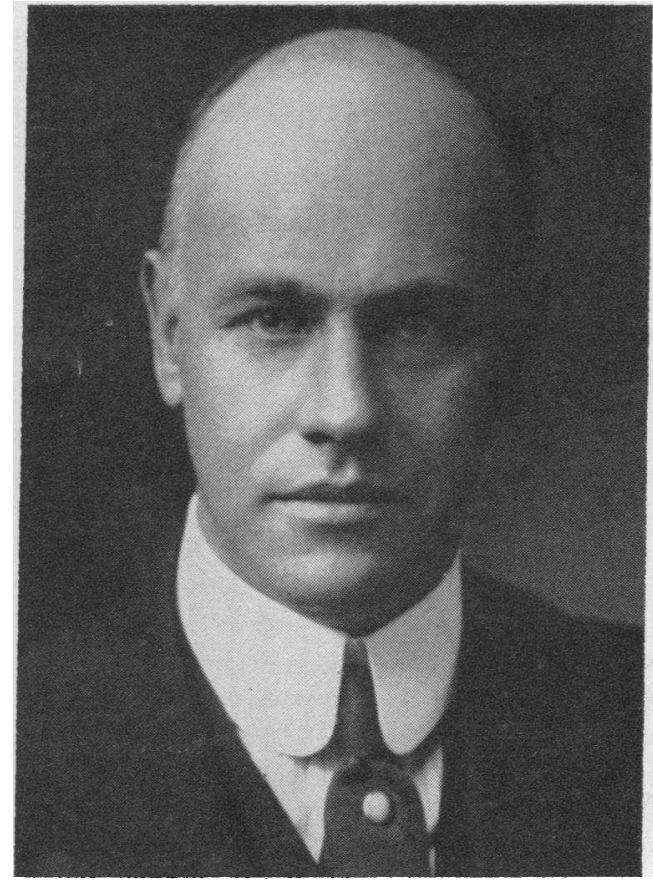

Henry A. Christian

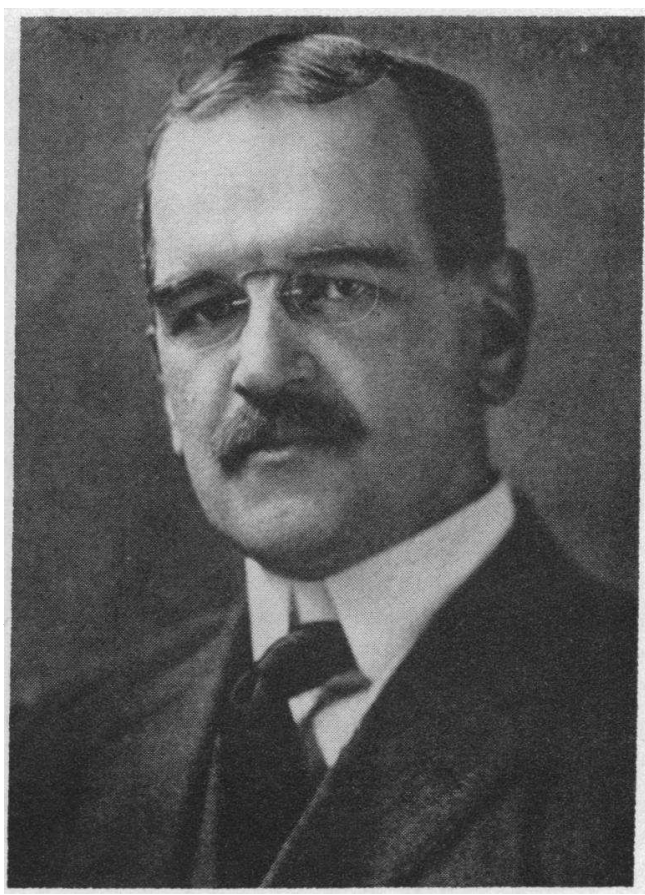

David L. Edsali 


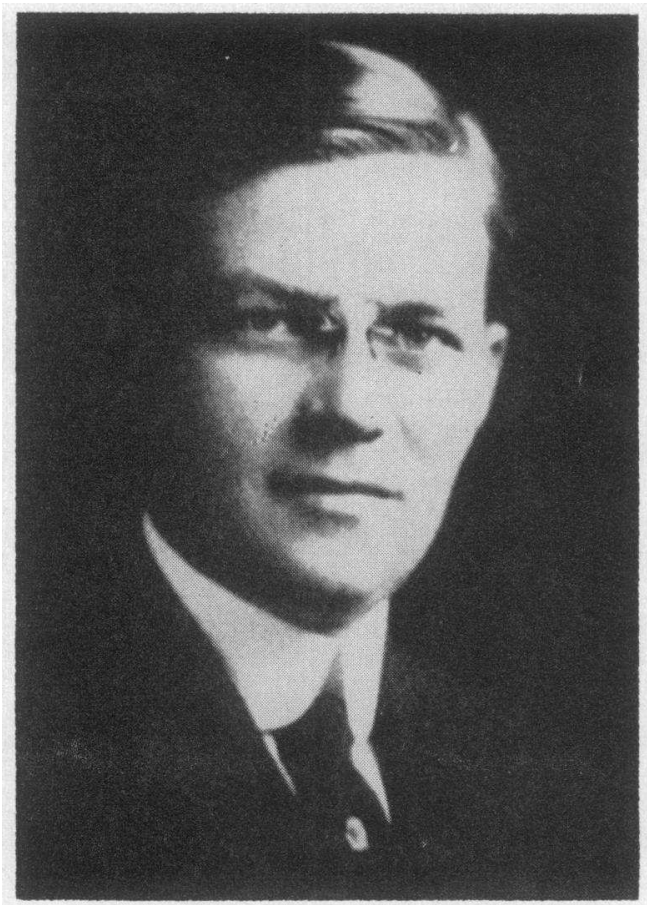

Albion Walter Hewlett

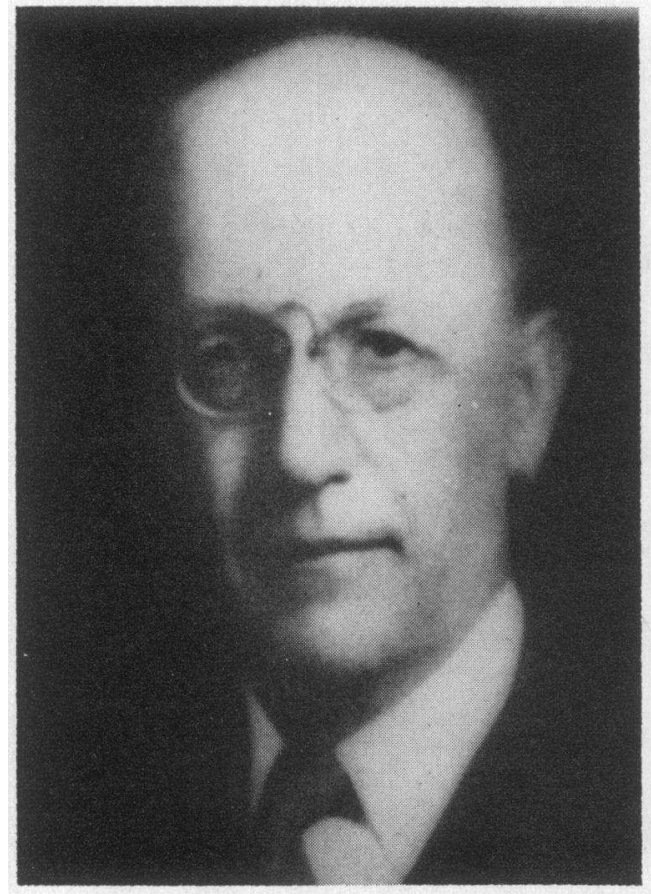

Joseph H. Pratt

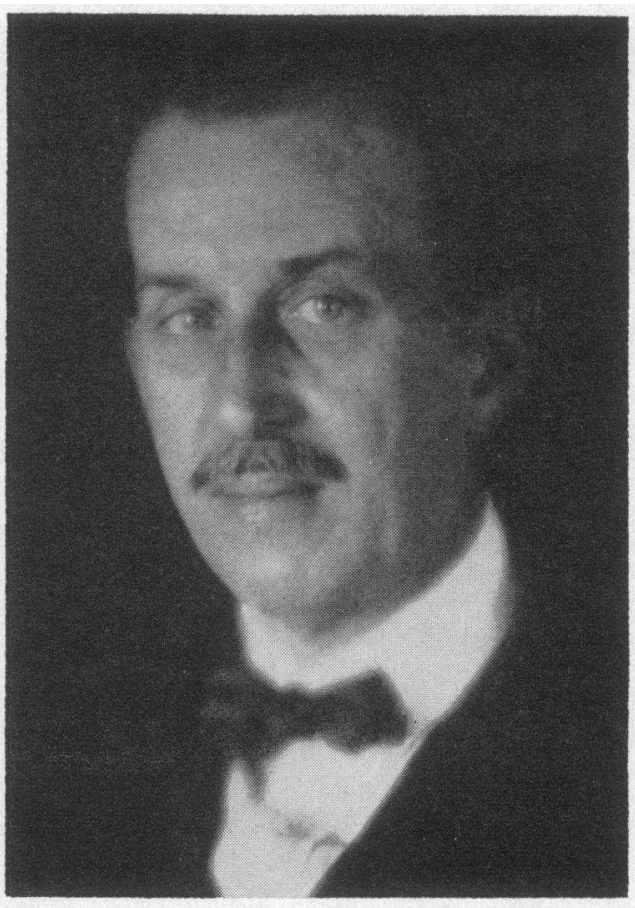

WARFIELD T. LONGCOPE

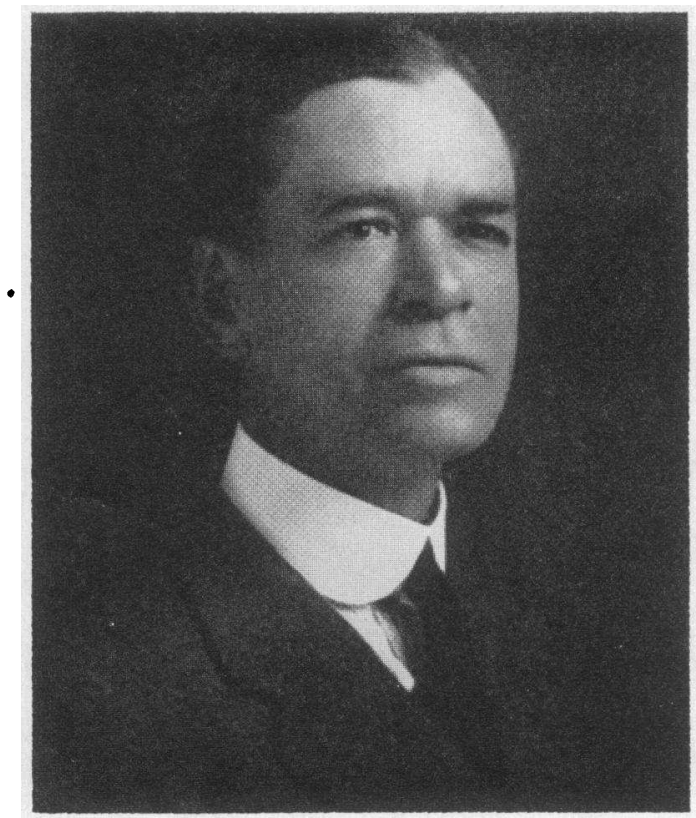

Wilder Tileston 


$$
\begin{aligned}
& \text { Yew Willand totel, Washong ton, D.C., } \\
& \text { may } 11,1908 \text {. }
\end{aligned}
$$

At 3:30 p.in. He following genttemen, Drs.D. L.

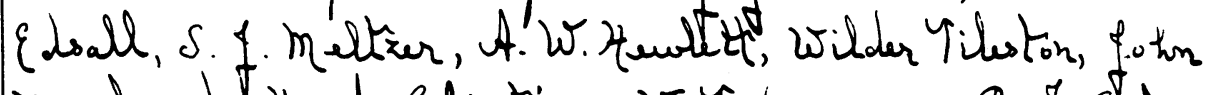
Howland, H. At. Chistian. W. T. Jongcope, R. I. Cole, E. Lliman, A. A. Capps, T. C. Janew ay, 25. I. C.aluert, F. L. Miller, \&. Sailer, martion Fischer, E. A. Locke, and Mark Richardison met in response to a letter of invitution sent out by a committac compased of the tollowing, 9. L. Edoult, H. A. Chistian, S. I. Meltizer, 1) H. Cralt, W. T. Kongcope, R. \&. Cok, Wilder Tilestor, 5. A. Capps, A. W. He twalett, for the organix ation of a new. socicty whase propasid scope had twen outtined in a ircular litter.

This muting was culled to arder by Dr. D. S. Edoall of Philadelphia.

Dr. Edsall was then elected tomparary hairman, Dr. H. At. Christian of Boston Temparary secoetary.

the (hairman stated that the First. Hing to be considered was the achoption of a consctiction, and that a committee composed of Drs. Song cope, Teeltzer. and Christian had prepared a constitution for consideration by the society.

Der. I. L: Mither of Chicago moved that the constitu. tion be read hy siongle articles. Seconded. Carried.

Dor. T.C. Lametway of new york moved that in arder to saure time a vite should not be taken

\section{Minutes of the Society's Charter Meeting}

Page 5 from the Society's first record book (there are now five) in which the minutes of the charter meeting of 1908 and all annual meetings until 1922 were recorded in longhand by the secretaries. The page reproduced above was written by Dr. Henry A. Christian who served as secretary from 1908 to 1910. 

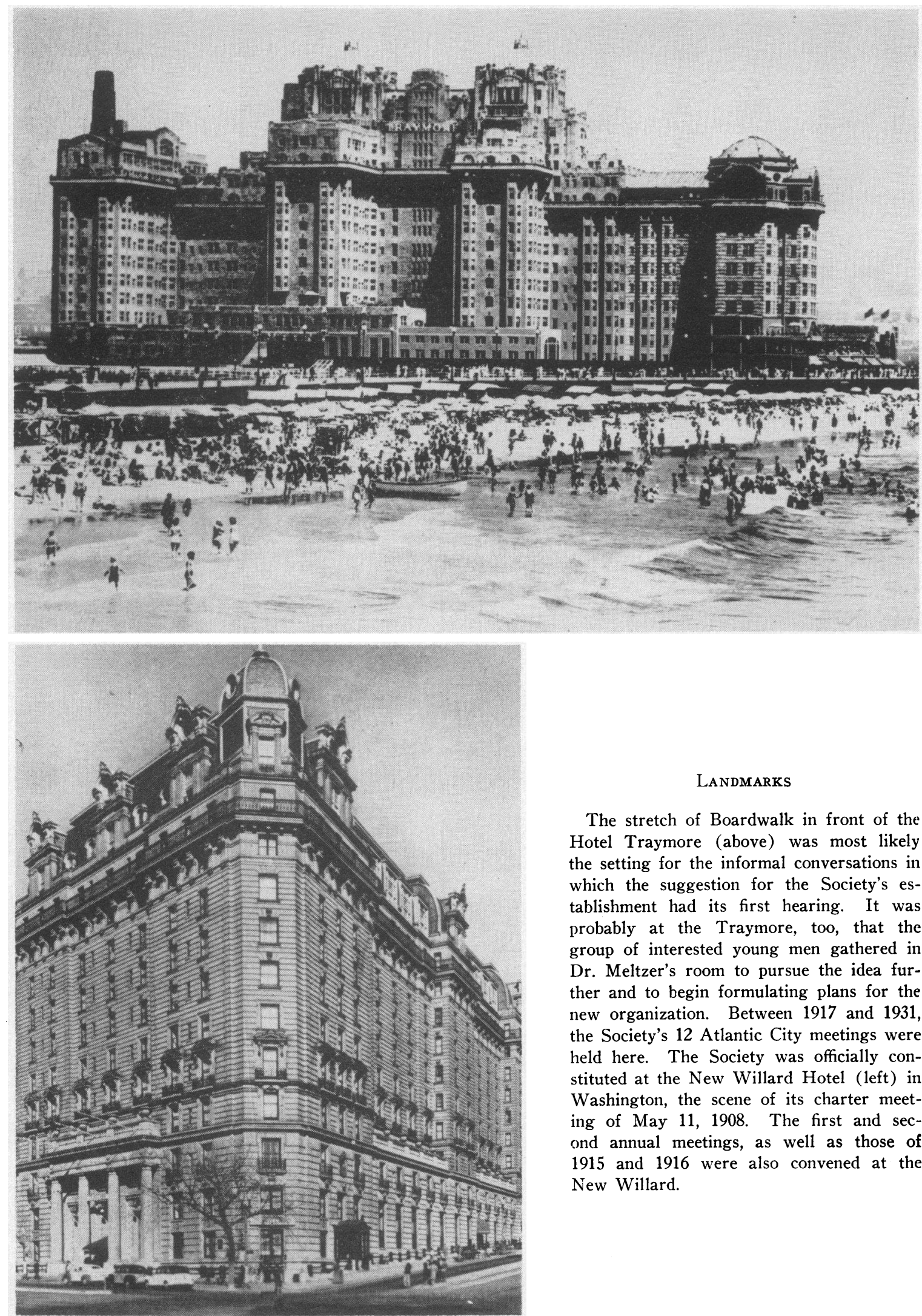

\section{LANDMARKS}

The stretch of Boardwalk in front of the Hotel Traymore (above) was most likely the setting for the informal conversations in which the suggestion for the Society's establishment had its first hearing. It was probably at the Traymore, too, that the group of interested young men gathered in Dr. Meltzer's room to pursue the idea further and to begin formulating plans for the new organization. Between 1917 and 1931, the Society's 12 Atlantic City meetings were held here. The Society was officially constituted at the New Willard Hotel (left) in Washington, the scene of its charter meeting of May 11, 1908. The first and second annual meetings, as well as those of 1915 and 1916 were also convened at the New Willard. 


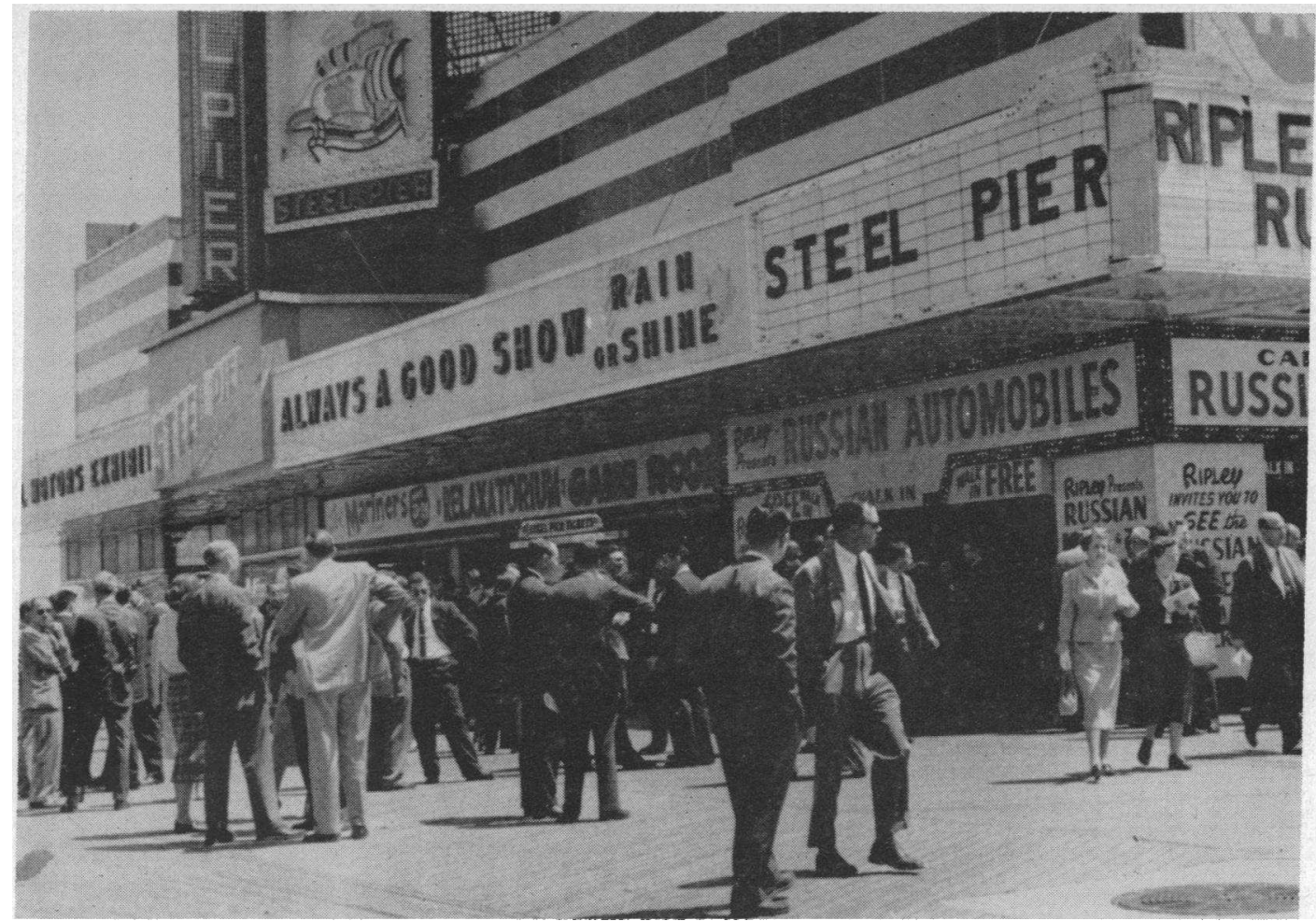

Between the ACts

When the mass of new knowledge threatened to cause mental indigestion, the audience often adjourned temporarily to the Boardwalk to discuss, argue, or simply relax before returning for the next paper.

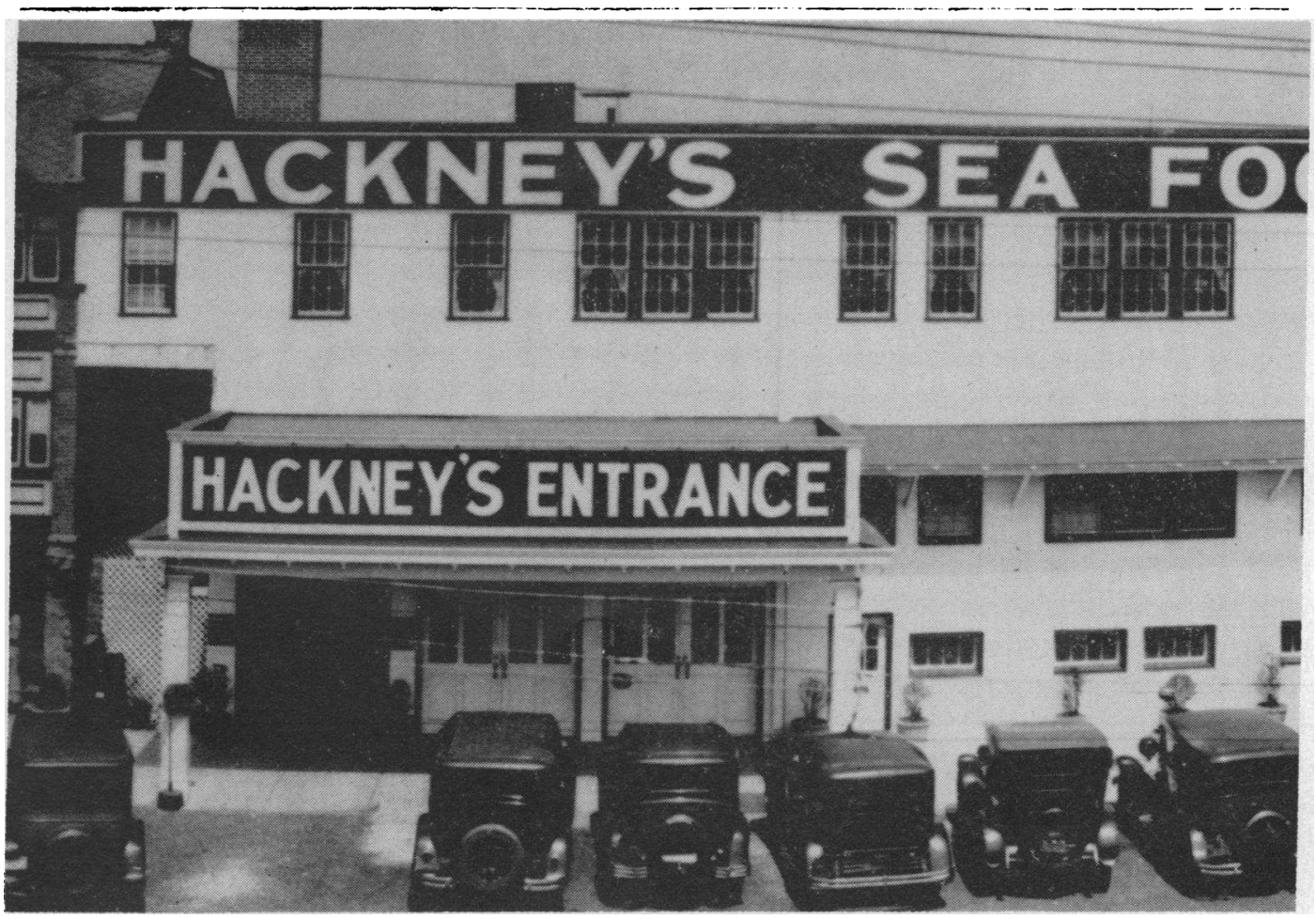

After Hours: Dinner and Debate

Hackney's Shore Dinners, a traditional eating place for Society members in the "good old days," was the setting for lively post-meeting discussions on Monday evenings after adjournment of the scientific sessions. The photograph above is probably of the 1920's vintage, although Society members have continued to patronize Hackney's more or less en masse up to the present. 

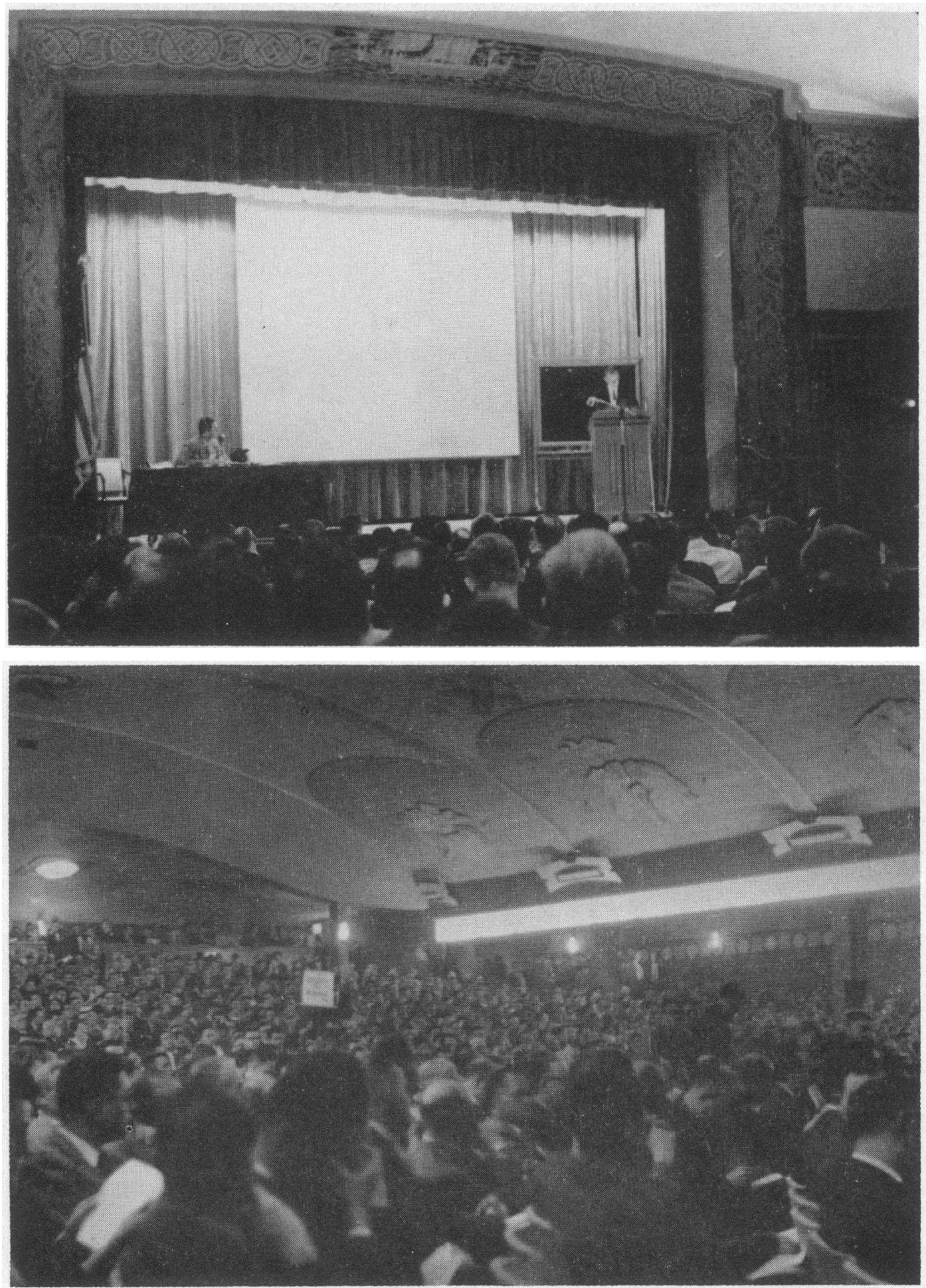

Intimate Informality Vs. Audience Accommodation

Some idea of the meaning of the controversy over the Society's 1950 move to the Steel Pier Theater can be derived from the views of the two meeting places shown above. At the top is the Viking Room of the Haddon Hall Hotel during one of the 1959 joint Society-American Federation for Clinical Research section meetings. The Viking Room, and the somewhat larger Vernon Room of Haddon Hall were the settings for most of the Society's annual meetings between 1932 and 1950 . The prevailing opinion among members active during that period is that these meeting places, in distinct contrast to the auditorium of the Steel Pier Theater (below) provided an atmosphere conducive to informal discussion of papers. The move to the Steel Pier was made, primarily, in response to the large postwar audiences. The picture of the Viking Room was taken from the back row; that of the Steel Pier auditorium, from the front row looking back. 

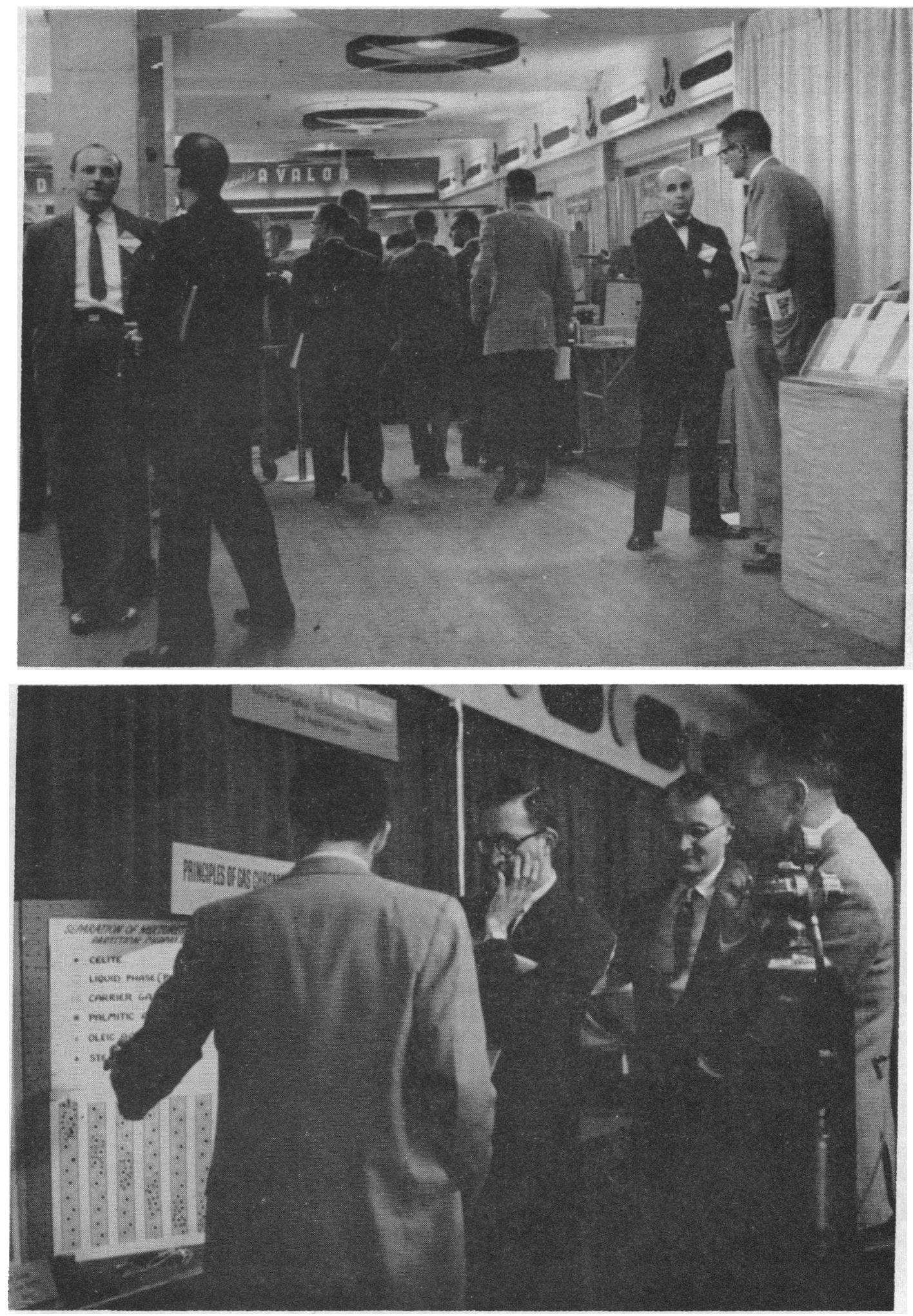

People at an Exhibition

With the move to the Steel Pier, another feature was added to Society programs-the annual scientific exhibits. Displays of scientific instruments and apparatus were introduced on a trial basis for the May meetings of 1952 and 1953 and at the present time are a regularly-scheduled addition to the programs. Exhibits are solicited by a committee of the Society, with final selection being made by the president in a manner similar to the selection of papers for the scientific program. Displays prepared by both commercial and institutional groups have been included. Pictured above is a general view of the exhibit lobby of the Steel Pier Theater (top) and one of the displays included on the 1959 exhibit program (bottom). 

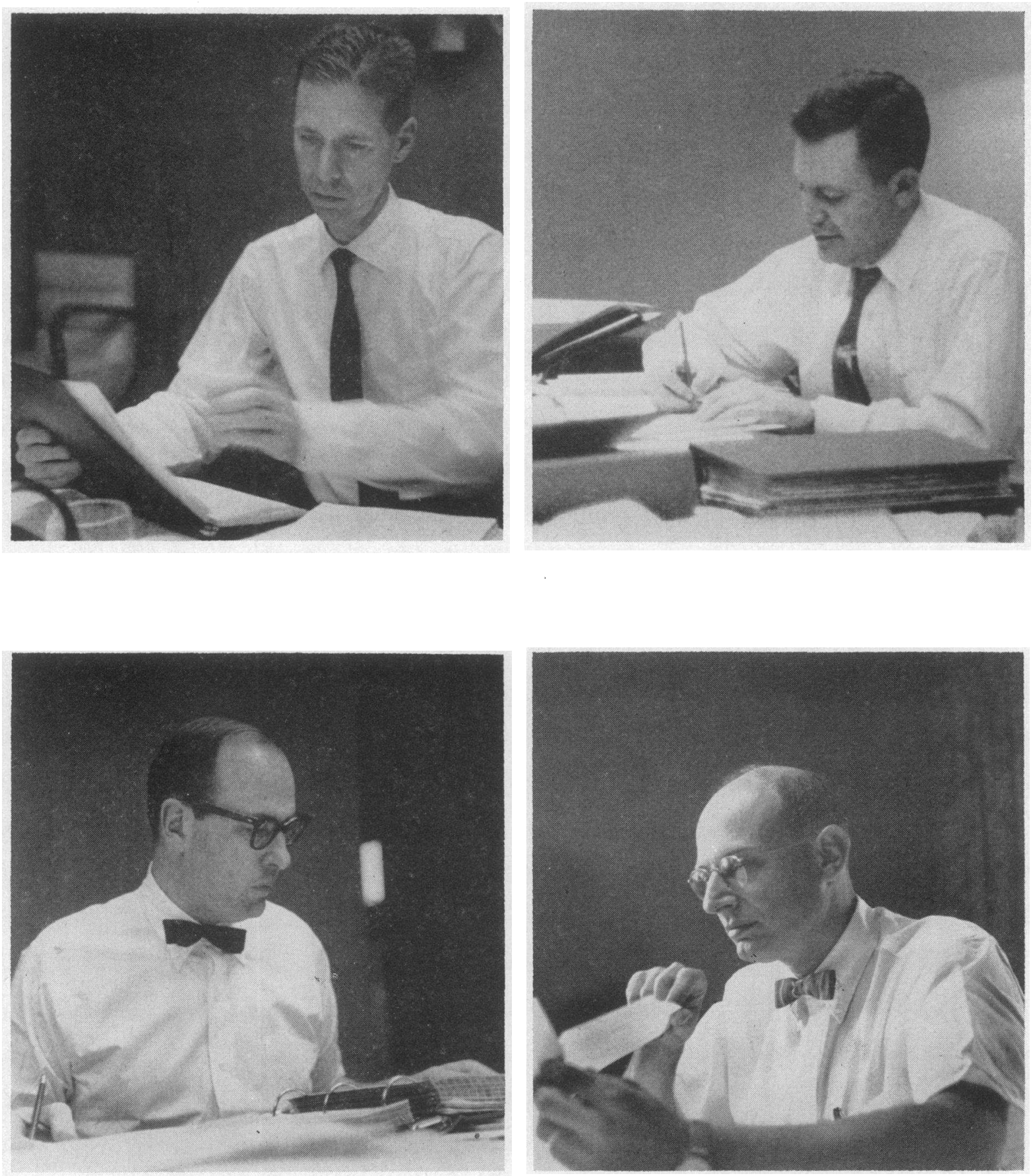

The Council of the Society, 1959: Officers

Photographs of the Council were taken during the 1959 meeting. The members are: (top left) Dr. John A. Luetscher, President; (top right) Dr. Saul J. Farber, Secretary-Treasurer; (bottom left) Dr. Vincent P. Dole, Vice President; and (bottom right) Dr. Philip K. Bondy, Editor-in-Chief of the Journal of Clinical Investigation. 

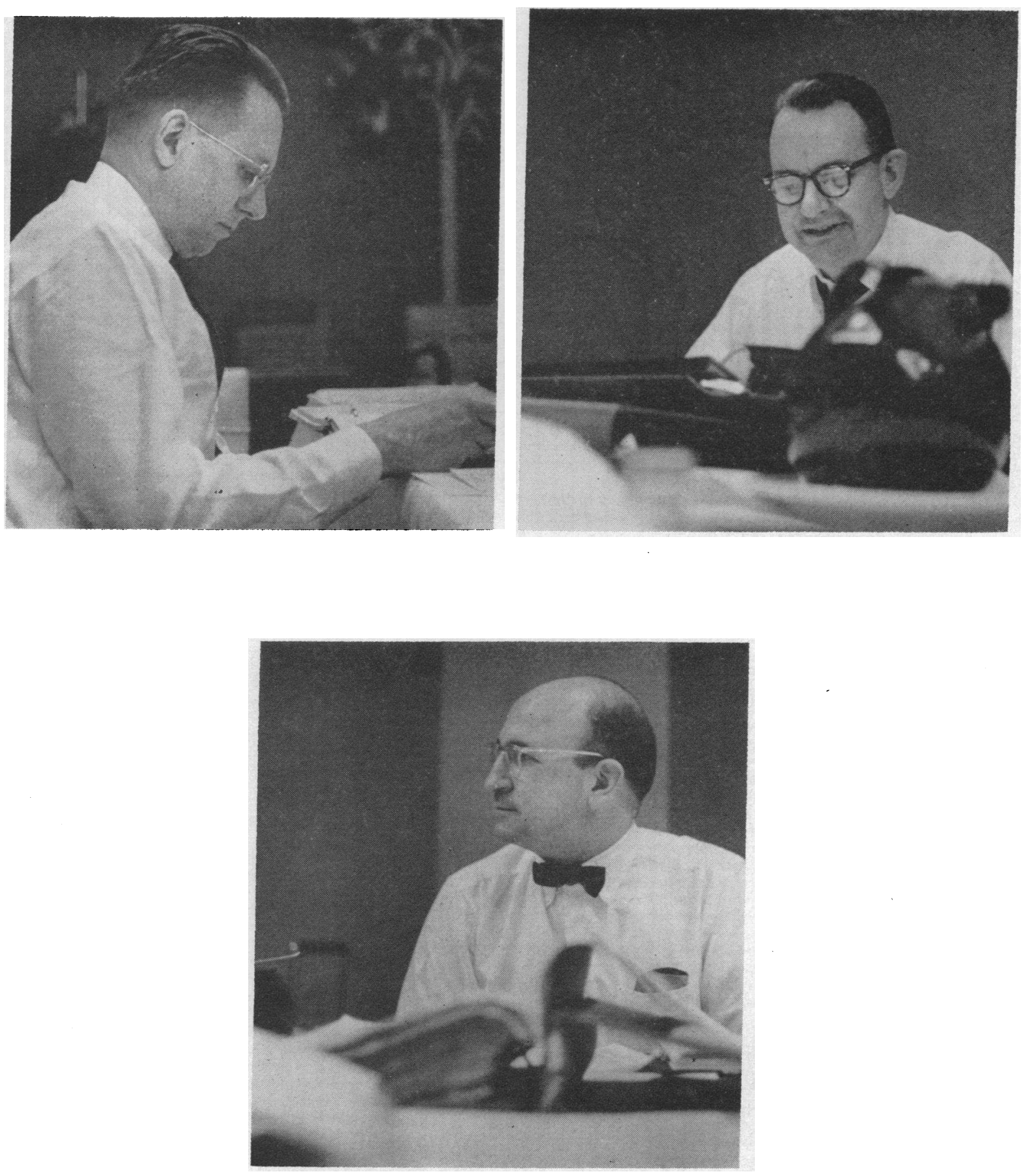

The Council of The Society, 1959: Councillors

The councillors, in order of election, are: (top left) Dr. C. Lockard Conley, 1957-1959; (top, right) Dr. John V. Taggart, 1958-1960; and (below) Dr. Harold S. Ginsberg, 1959-1961. 